\title{
A PARAMETRIC STUDY ON THE EFFECTIVENESS OF THE NSM TECHNIQUE FOR THE FLEXURAL STRENGTHENING OF CONTINUOUS RC SLABS
}

\author{
Matteo Breveglieri ${ }^{1}$, Joaquim A. O. Barros ${ }^{2 *}$, Gláucia M. Dalfré ${ }^{3}$, Alessandra Aprile ${ }^{4}$
}

${ }^{1} \mathrm{PhD}$ Student, Dep. of Eng., University of Ferrara, Via Saragat, 1 - 44100 Ferrara, Italy, matteo.breveglieri@ unife.it

2*Associate Prof., ISISE, Dep. of Civil Eng., University of Minho, Guimarães, Portugal, barros@ civil.uminho.pt, corresponding Author ${ }^{3} \mathrm{PhD}$ Student, ISISE, Dep. of Civil Eng., University of Minho, Guimarães, Portugal, gmdalfre@ civil.uminho.pt

${ }^{4}$ Assistant Professor, Dep. of Eng., University of Ferrara, Via Saragat, 1 - 44100 Ferrara, Italy, alessandra.aprile@ unife.it

\begin{abstract}
Recent experimental research has shown that Near Surface Mounted (NSM) technique has high potential to increase the load carrying capacity of continuous reinforced concrete (RC) slabs. This flexural strengthening technique is based on the installation of rectangular cross sectional carbon fibre reinforced polymer (CFRP) laminates into thin slits opened onto the top concrete cover at the intermediate supports and in the bottom concrete cover in the tensile zones.

However, the linear-elastic behaviour of the CFRP laminates, and the possibility of occurring premature detachment of the concrete cover that includes these laminates can compromise, not only the flexural strengthening effectiveness of the NSM technique, but also the moment redistribution and the ductility performance of this type of structures.

To evaluate the influence of the concrete strength class, the percentage of existing longitudinal tensile reinforcement and the percentage of CFRP on the strengthening effectiveness, moment redistribution capacity and ductility performance, a parametric study was carried out by executing material nonlinear analysis with a FEM-based computer program, which predictive performance was calibrated using the results of a previous experimental program.
\end{abstract}

Keyword: A. Laminates; C. Finite Element Analysis (FEA); D. Mechanical testing

\section{INTRODUCTION}

Extensive research has been conducted on the strengthening of reinforced concrete (RC) structures using an externally bonded fiber reinforced polymer reinforcement technique (EBR-FRP), based on the use of FRP sheets or laminates 
applied on the faces of the elements to strengthen. The available research in this topic has revealed that EBR-FRP strengthened systems tend to debond at relatively low strain of the FRP, mainly when high percentage of FRP is necessary to increase the load carrying capacity of the structure to strengthen (Barros et al. 2007, Oehlers et al. 2007). When applied to statically indeterminate RC beams and slabs, the premature debond of the EBR-FRP systems, as well as the linear-elastic brittle failure behavior of these composite materials, can be a serious restriction, not only in terms of attaining the aimed load carrying capacity for the strengthened structure, but also in terms of assuring the required level of ductility and moment redistribution (Spadea et al. 1998, Oehelers et al. 2007, Casadei et al. 2003, Arduini et al. 1997).

The first research projects carried out with RC continuous elements were conducted using the EBR technique, and these strengthened elements have showed the tendency to fail by premature plate debonding (Vasseur et al. 2007, El-Rafaie $e t$ al. 2004, Sowa et al. 2005, Oehlers et al. 2004, Aiello et al. 2007). In some of these works a significant moment redistribution capacity was claimed for FRP-strengthened elements (Oehlers et al. 2004, Aiello et al. 2007), but a recent research indicates that the moment redistribution in continuous beams can decrease up to 50\% (Rinaldi et al. 2008).

The recent achievements in terms flexural strengthening effectiveness of the near surface mounted technique (NSM) enlarge the potentialities of FRP systems for new types of applications (Barros and Kotynia 2008). This technique is based on the use of circular or rectangular cross sectional bars of carbon or glass fiber reinforced polymer materials (CFRP or GFRP), installed into pre-cut grooves opened onto the concrete cover of the elements to be strengthened. The effectiveness of NSM technique derives from the relatively high bond performance between FRP bars and concrete substrate, mainly those with a rectangular cross section, due to its relatively high perimeter/area ratio (De Lorenzis and Nanni 2002, Täljsten et al. 2003, Blaschko 2003, Sena and Barros 2004, Bianco et al. 2009). Furthermore, the NSM technique does not require surface preparation, and provides higher protection to the environmental conditions and vandalism acts.

Tests on simply supported RC members strengthened with NSM CFRP laminates have shown that NSM laminates debond at much higher strains than EBR CFRP strengthening systems (Blaschko 2003, Barros and Fortes 2005, Barros et al. 2007). Therefore NSM strengthened members are expected to have a behavior that is more ductile than EBR strengthened members.

Since the majority of the tests carried out with NSM strengthened members have simply supported conditions, there is a lack of experimental and theoretical studies on the moment redistribution of statically indeterminate RC members strengthened according to the NSM technique. Relevant tests on continuous RC beams strengthened with NSM technique were conducted by Liu (2005) and Liu et al. (2006). Nine two-span continuous beams were strengthened in the hogging region (intermediate support) with NSM high yield steel strips or with NSM CFRP strips and tested to 
determine the moment redistribution and ductility performance of the retrofitted elements. The results showed that the beams strengthened with NSM high yield steel and NSM CFRP laminates achieved a moment redistribution percentage of $39 \%$ and $32 \%$, respectively. Additionally, it was found that the debonding strains when using NSM technique were considerably larger than those associated with EB plates, which justifies the relatively high moment redistribution levels observed in the NSM strengthened beams.

Bonaldo (2008) carried out an experimental program to assess the moment redistribution capacity of two-span RC slabs flexural strengthened with NSM CFRP laminates in the hogging region. The experimental program was composed of three series of three slab strips of two equal span lengths, in order to verify the possibility of maintaining moment redistribution levels of $15 \%, 30 \%$ and $45 \%$ when the load carrying capacity is increased in $25 \%$ and $50 \%$. It was found that the NSM strengthening system applied to the continuous RC slab strips provided a relatively low increment of the load carrying capacity (did not exceed $21 \%$ ) and the moment redistribution has decreased with the increase of the CFRP percentage. Additionally, this experimental program was analyzed using a FEM-based computer program in order to justify the relatively low performance of these strengthening systems, and an effective NSM flexural strengthening strategy was proposed (Dalfré and Barros, 2011a). It was verified that, to increase significantly the load carrying capacity of this type of slabs, the sagging region needs also to be strengthened, using, for instance, NSM CFRP laminates in the bottom tensile surface of the two spans of the slab. Additionally, the results suggest that, if the NSM strengthening system is designed properly and precautions are taken to prevent shear or debonding failure, relevant moment redistribution levels can occur up to the final failure these strengthened elements.

Recently, an experimental program composed by one reference RC slab (SL15) and two slab strips (SL15s25a and SL15s25b) strengthened in both hogging (intermediate support) and sagging regions (loaded sections) was carried out (Dalfré and Barros, 2009a). The amount and disposition of the steel reinforcement were the same as those used by Bonaldo (2008), designed to assure a moment redistribution of 15\%. The NSM CFRP systems applied in the flexural strengthened RC slabs were designed to increase in $25 \%$ to $30 \%$ the load carrying capacity of the reference slab, therefore these two slabs had a small difference in the percentage of CFRP applied in the sagging regions $\left(\rho_{f}^{S}=0.14 \%\right.$ in SL15s $25 \mathrm{a}$ and $\rho_{f}^{S}=0.17 \%$ in SL15s $25 \mathrm{~b}$ ). As a result, an average increment in the load carrying capacity of $29 \%$ was obtained. Additionally, it was found that the presence of the NSM CFRP flexural strengthening systems led to a decrease of the rotational ductility, but the displacement ductility was not detrimentally affected.

To contribute for a better understanding of the influence of the strengthening arrangement (hogging, sagging or both regions) and percentage of FRP in terms of load carrying capacity, moment redistribution capacity and ductility performance, a parametric study is carried out in the present work. This parametric study is performed by executing 
nonlinear analysis with a computer program based on the Finite Element Method (FEM), whose predictive performance is appraised by using the results obtained in the experimental program carried out by Bonaldo (2008).

\section{THE EXPERIMENTAL PROGRAM}

\subsection{Slab specimens and strengthening technique}

To assess the influence of the NSM CFRP flexural strengthening technique on the moment redistribution capacity of statically indeterminate RC slabs, an experimental program composed of nine $120 \times 375 \times 5875 \mathrm{~mm}^{3} \mathrm{RC}$ slabs of two equal spans was carried out by Bonaldo (2008). Three of the RC slabs were unstrengthened, forming a control set (SL15, SL30 and SL45), and six slabs were strengthened with CFRP laminates according to the NSM technique (SL15s25, SL15s50, SL30s25, SL30s50, SL45s25 and SL45s50). The notation adopted to identify each slab specimen is SLxsy, where $\mathrm{x}$ is the target moment redistribution percentage, $\eta(15 \%, 30 \%$ or $45 \%)$, s indicates that the slab is strengthened, and y represents the target increase of load carrying capacity for the slab strip (25\% or 50\%), provided by the adopted CFRP-strengthening configurations. According to the CEB-FIB Model Code (1993), the moment redistribution coefficient, $\delta=M_{\text {red }} / M_{\text {elas }}$, is defined as the ratio between the moment in the critical section after redistribution $\left(M_{\text {red }}\right)$ and the elastic moment $\left(M_{\text {elas }}\right)$ in the same section calculated according to the theory of elasticity, and $\eta=(1-\delta) \cdot 100$ is the moment redistribution percentage. Figure 1 and Table 1 show the geometry, the steel reinforcement and strengthening details of the cross sections of the slabs of the experimental program. In this table, the equivalent reinforcement ratio, $\rho_{s, e q}=A_{s l} / b d_{s}+\left(A_{f} E_{f} / E_{s}\right) /\left(b d_{f}\right)$, is also indicated, where $b$ is the slab strip width, $d_{s}$ and $d_{f}$ are the effective depth of the longitudinal steel bars and CFRP systems, respectively, $A_{f}$ and $E_{f}$ are the cross sectional area and the Young's Modulus of the CFRP systems, respectively, and $A_{s l}$ and $E_{s}$ are the cross sectional area and the Young's Modulus of the longitudinal tensile steel bars, respectively.

These reinforcement arrangements were designed for a load $(F)$ of $50.82 \mathrm{kN}$, which is $10 \%$ higher than the load for the verification of deflection service limit state according to ACI 318 (2004). The steel reinforcement was designed according to the Eurocode 2 (2004) recommendations, while the NSM CFRP strips were designed following the suggestions of ACI 440 (2008). The design details of these slabs can be found elsewhere (Bonaldo 2008). Figure 1 also represents the loading and the support conditions. Six LVDTs were equally distributed along the two spans of the slab (the LVDTs at the left and right loaded sections have the reference numbers 60541and 18897, respectively). Electrical 
resistance strain gauges, SGs, were installed on internal steel bars, concrete surfaces and on CFRP laminates, according to the arrangement indicated elsewhere (Bonaldo 2008).

The properties of the intervening materials were experimentally determined. The concrete compressive strength was assessed with compression tests at 28 days, and it was obtained 40.07, 35.99 and 41.41 MPa for the SL15, SL30 and SL45 series, respectively. The steel bars had an average yield stress of $439.60 \mathrm{MPa}$ and a tensile strength of 565.30 MPa. Finally, the CFRP laminates, of $1.4 \times 10 \mathrm{~mm}^{2}$ cross section, had an average ultimate tensile stress of $2867 \mathrm{MPa}$, and an ultimate tensile strain of $17.70 \%$.

\subsection{Relevant results}

The relationship between the applied load $(F)$ in each loaded section of the two spans of the slab and the corresponding deflection, for the SL15 series, is represented in Figure 2. The main obtained results of the performed tests for the three series are included in Table 2 where: $\Delta F_{\text {Tar }}$ is the target increase of the load carrying capacity, $\bar{F}_{\text {max }}$ is the maximum value of the average of the forces applied in the two spans, and $\bar{R}_{L, \bar{F} \text { max }}$ and $\bar{R}_{C, \bar{F} \text { max }}$ are the reactions at the lateral and at central supports, respectively, at $\bar{F}_{\max }$. Table 2 also includes the negative moment $M_{E x p}^{-}$and the moment redistribution percentage $\eta$ at the steel yield initiation in the loaded sections. In round brackets in the columns of $\bar{F}_{\max }$ and $M_{E x p}^{-}$is indicated the corresponding increase percentage registered experimentally. It is verified that an average increase of $8 \%$ and $16 \%$ was obtained for the load carrying capacity of the slabs strengthened for an increase of the negative bending moment of $25 \%$ and $50 \%$, respectively. If laminates are only applied in the hogging region a plastic failure mechanism is almost coinciding with the formation of the plastic hinge in the hogging region, which is responsible for the small increase in terms of slab's load carrying capacity. A detailed justification for the relatively small increase of load carrying capacity provided by this strengthening strategy is justified elsewhere (Dalfré and Barros, 2011a).

Furthermore, for the sake of example, Figure 3 shows the relationship between $\eta(\%)$ and the average applied load for the SL15 series, where it is visible that $\eta$ has decreased with the increase of the percentage of CFRP laminates. For SL15 series the moment redistribution is almost nonexistent. In this Figure, $\bar{F}_{c r}, \bar{F}_{y}^{H}$ and $\bar{F}_{y}^{s}$ are the load at crack initiation, and at yield initiation of the hogging and sagging regions, respectively.

To increase significantly the load carrying capacity of this type of slabs, the positive resisting bending moments need also to be increased, using, for instance, NSM CFRP laminates in the bottom tensile surface of the two spans of the slab. In fact, adopting a flexural strengthening strategy composed by CFRP laminates applied in both hogging and sagging 
regions, Dalfré and Barros (2011b) obtained an increase in terms of load carrying capacity that has exceeded the target value $(25 \%)$, and the moment redistribution capacity was not significantly affected.

\section{PREDICTING THE BEHAVIOUR OF CONTINUOUS NSM FLEXURAL STRENGTHENED RC SLABS}

\subsection{Introduction}

One of the main objectives of the present research is the execution of a parametric study to assess the influence of relevant parameters on the load carrying capacity, moment redistribution level and ductility performance of statically indeterminate RC slabs strengthened according to the NSM technique. However, the reliability of this study requires the use of a computational tool capable of simulating the relevant aspects of this structural system. For this purpose, a FEM-based computer program that includes several constitutive models for the nonlinear analysis of RC structures was selected (Barros et al., 2008), and its predictive performance is appraised on the simulation of the tests carried out by Bonaldo (2008), already briefly presented in the previous chapter.

For these simulations a constitutive model able to simulate the concrete crack initiation and crack propagation, the nonlinear concrete compression behavior, the elasto-plastic behavior of steel reinforcements and the elastic-brittle failure behavior of FRP elements was selected. According to the selected model, a concrete slab is considered as a plane shell formulated under the Reissner-Mindlin theory (Barros and Figueiras, 2001). In this numerical approach the shell element is discretized in layers and each layer is considered in a plane stress state. A detailed description of this model can be found elsewhere (Barros et al., 2008).

\subsection{Predictive performance of the model}

Due to the structural symmetry, only half of the slab is considered in the numerical simulations. Figure 4 shows the eight node finite element mesh adopted, and the support conditions. The slab thickness is discretized in 20 layers. The values of the parameters of the constitutive model are indicated in Tables 3 and 4 (see also Figures 5 and 6 for the comprehension of the physical meaning of some parameters). To take into account that at the cracked section the stress in the steel reinforcement is higher than between cracks, and considering that the model evaluates the average strains in the steel, the stress reduction factors for the $\sigma_{s y}, \sigma_{s h}$, and $\sigma_{s u}$ (Figure 6) proposed by Stevens (1987) were adopted:

$\sigma_{s y}=\sigma_{s y}^{\exp }-3 \Delta \sigma_{y c r} ; \sigma_{s h}=\sigma_{s h}^{\exp }-\Delta \sigma_{y c r} ; \sigma_{s u}=\sigma_{s u}^{\exp }-\Delta \sigma_{y c r} ; \Delta \sigma_{y c r}=75 \phi_{s} / f_{c t}$ 
where $\sigma_{s y}^{\mathrm{exp}}, \sigma_{s h}^{\mathrm{exp}}$ and $\sigma_{s u}^{\mathrm{exp}}$ are the values registered experimentally, $f_{c t}$ is the concrete tensile strength in MPa and $\phi_{s}$ is the bar diameter (or equivalent bar diameter) in $\mathrm{mm}$. The values in Table 4 are already affected by these reduction factors. The CFRP laminates were assumed as an isotropic material of an elasticity modulus of $160 \mathrm{GPa}$ and null Poisson's coefficient, since the consideration of their real orthotropic properties has marginal influence in terms of their contribution for the behavior of NSM strengthened RC slabs. Figure 7 compares the numerical and experimental loaddeflection curves for the slabs of SL15 series, where it is visible the quite good predictive performance of the adopted model. The effectiveness of the model is also visible on the evaluation of the strains in the steel bars, concrete and CFRP strips, as shown in Figure 8. Due to lack of space only SL15s50 slab is analyzed in this work, but similar good predictive performance was obtained for all the tested slabs (Dalfré and Barros, 2009b).

\section{PARAMETRIC STUDY}

\subsection{Introduction}

The computer program, which good predictive performance on the simulation of the behavior of the type of structures in analysis was confirmed in the previous chapter, was adopted to execute a parametric study for the evaluation of the influence on the load carrying and moment redistribution capacities of the following parameters: concrete strength class, the percentage of existing longitudinal tensile reinforcement, strengthening configuration and percentage of CFRP laminates.

\subsection{Strengthening arrangements and numerical simulations}

The arrangements of the steel reinforcement, dimensions of the cross section, support and load conditions are the same adopted in the experimental/numerical program for the reference slab strip of SL15 series (Figure 1). However, distinct strengthening arrangements were applied in the hogging $(\mathrm{H})$ and sagging regions $(\mathrm{S})$, as shown in Figure 9 and Table 5. In the parametric study, the mechanical properties adopted for the concrete strength classes $(\mathrm{C} 12 / 15, \mathrm{C} 25 / 30$ or $\mathrm{C} 35 / 45)$ were determined following the recommendations of Eurocode 2 and CEB-FIP Model Code 90 (Table 6). The values of the parameters adopted for the constitutive model used to simulate the behavior of the steel bars are those included in Table 4. For the numerical simulations, the CFRP laminates of $1.4 \times 20 \mathrm{~mm}^{2}$ cross sectional area were assumed as an isotropic material with an elasticity modulus of $165 \mathrm{GPa}$ and null value for the Poisson's coefficient, since the consideration of their real anisotropic properties has marginal influence in terms of their contribution for the behavior of NSM strengthened RC slabs. 


\subsection{Relevant results}

The slab strips can be classified in three different groups, due to the distinct adopted strengthening arrangements: (a) applied in the hogging region, (b) applied in the sagging regions and (c) applied in both hogging and sagging regions. The notation adopted to identify a slab strip is SLx_y_w_z, where $\mathrm{x}$ is the moment redistribution percentage, $\eta$ (15\%), $\mathrm{y}$ is the concrete strength class $(\mathrm{C} 12 / 15, \mathrm{C} 25 / 30$ or $\mathrm{C} 35 / 45)$, and $\mathrm{w}$ and $\mathrm{z}$ indicate the number of NSM CFRP laminates applied in the sagging or hogging regions, respectively. Therefore, SL15_30_4_2 represents a slab with a target $\eta$ $=15 \%$, made by a concrete of $f_{c k}=30 \mathrm{MPa}$ (in cubic specimens), and strengthened with 4 and 2 laminates in the sagging and hogging regions, respectively.

In the present parametric study, the formation of the second hinge (at the loaded sections, in the sagging regions) was assumed as the ultimate failure condition, therefore the numerical simulations were interrupted when the yield strain was attained in the tensile steel bars positioned in the sagging region.

Tables 7 to 9 resume the results obtained numerically for two scenarios: when a plastic hinge formed at the hogging region (at intermediate support zone, $\mathrm{H}$ ); when a plastic hinge formed at the sagging region (at loaded section, S). In these Tables, $F_{y}^{H}$ and $F_{y}^{S}$ are the loads at the formation of the plastic hinge at $\mathrm{H}$ and S, respectively, $\Delta_{y}^{H}$ and $\Delta_{y}^{S}$ are the deflections for $F_{y}^{H}$ and $F_{y}^{S}$, respectively, $\varepsilon_{c}^{H}$ and $\varepsilon_{c}^{S}$ are the concrete compressive strains at $\mathrm{H}$ and $\mathrm{S}, \varepsilon_{s}^{H}$ and $\varepsilon_{s}^{S}$ are the maximum strains in steel bars at $\mathrm{H}$ and $\mathrm{S}$, respectively, $\varepsilon_{f}^{H}$ and $\mathcal{E}_{f}^{S}$ are the strains in the CFRP laminates at $\mathrm{H}$ and $\mathrm{S}$ and $\eta$ is the moment redistribution percentage at $F_{y}^{S}$.

In the cases where the NSM CFRP laminates are only applied in the hogging region $(\mathrm{H})$, the failure mechanism is governed by yielding of internal reinforcement in the hogging region, followed by the premature formation of the second hinge at the loaded section. In this case, the deflection at the formation of the plastic hinge in the hogging region and the deflection amplitude between the formation of both plastic hinges have decreased with the increase of the equivalent reinforcement ratio (due to the increase of CFRP percentage), (Breveglieri 2009). According to the results, no significant increase of load carrying capacity is obtained, which is in agreement to the experimental results registered by Bonaldo (2008).

In the cases where the NSM CFRP laminates are only applied in the sagging region (S), the formation of the first hinge occurs for similar deflections, regardless the percentage of laminates in the sagging region, $\rho_{f}^{S}$. However, the deflection amplitude between the formation of a plastic hinge in sagging and hogging regions has increased with the increase of $\rho_{f}^{S}$. The increase of load carrying capacity is now more pronounced with the percentage of laminates than in the previous cases. 
Finally, in the cases where the NSM-CFRP laminates are applied in both regions ( $\mathrm{H}$ and $\mathrm{S})$, the amplitude of deflection between the formation of the plastic hinges in the hogging and sagging regions is almost the same for the analyzed cases. The increase of load carrying capacity with the percentage of laminates, $\rho_{f}$, is the highest amongst the three analyzed configurations, mainly up to the initiation of the plastic hinge in the hogging region.

Concerning to the concrete strength classes adopted in this study, it can be noted that the overall behavior of the strengthened slab strips was not significantly affected by this parameter.

\subsection{The load carrying capacity index}

The load carrying capacity index $(\lambda)$ is defined as the ratio between the load carrying capacity of the strengthened $\left(F_{\text {streng }}\right)$ and the corresponding reference $\operatorname{slab}\left(F_{r e f}\right), \lambda=F_{\text {streng }} / F_{\text {ref }}$, where $F$ is the force at the initiation of the second plastic hinge. The relationships between $\lambda$ and $\rho_{s, e q}$ in the hogging $\left(\rho_{s, e q}^{H}\right)$ and sagging $\left(\rho_{s, e q}^{S}\right)$ regions are represented in Figure 10 and Table 10. In this figure the relationships between $\lambda-\rho_{f}^{S}$ and $\lambda-\rho_{f}^{H}$ are also indicated, where $\rho_{f}^{S}$ and $\rho_{f}^{S}$ are the percentage of CFRP in the sagging and hogging regions, respectively. As expected, the load carrying capacity of the strengthened slabs increases with $\rho_{s, e q}^{S}$ and $\rho_{s, e q}^{H}$, but the increase of $\lambda$ is more pronounced with $\rho_{s, e q}^{S}$. For the slabs only strengthened in the hogging region (Figure 10a), the increase of $\lambda$ is less than $10 \%$, which is in agreement to the experimental results obtained by Bonaldo (2008). In the slab strips only strengthened in the sagging region (Figure 10b), a maximum increase of $17 \%$ was obtained. As expected, to increase significantly the load carrying capacity of this type of slabs, a flexural strengthening strategy composed by CFRP laminates applied in both hogging and sagging regions should be adopted. According to the results, a maximum increase of $28 \%$ was obtained, which is in agreement to the experimental results obtained by Dalfré and Barros (2009a). Additionally, the analysis of the results shows that the increase of the load carrying capacity is not so significant due to the relatively high steel reinforcement ratio $\left(\rho_{s}^{H}=1.60\right.$ and $\left.\rho_{s}^{S}=1.71\right)$ adopted in the analysed the slab strips. If smaller values of $\rho_{s}^{H}$ and $\rho_{s}^{S}$ are used, higher increase of $\lambda$ is expected with the increase of $\rho_{f}^{S}$ and $\rho_{f}^{H}$ (Barros and Kotynia 2008).

\subsection{Displacement Ductility Index}

The displacement ductility $(\Delta)$ is defined as the ratio between the displacements of the loaded section at the formation of the second and the first hinges $\left(\Delta=\Delta_{2 n d} / \Delta_{1 s t}\right)$. The displacement ductility index $\left(\mu_{\Delta}\right)$ is expressed as the ratio between the displacement ductility of the strengthened $\left(\Delta_{\text {streng }}\right)$ and the reference $\left(\Delta_{\text {ref }}\right)$ slab strips $\left(\mu_{\Delta}=\Delta_{\text {streng }} / \Delta_{\text {ref }}\right)$. 
The relationships $\mu_{\Delta}-\rho_{s, e q}^{S}$ and $\mu_{\Delta}-\rho_{s, e q}^{H}$ are represented in Figure 11, while the corresponding obtained values are included Table 10. In this figure it is also indicated the relationships $\mu_{\Delta}-\rho_{f}^{S}$ and $\mu_{\Delta}-\rho_{f}^{H}$. From the results it can be noted that the displacement ductility index decreases with the increase of the percentage of the CFRP laminates in the hogging region. In fact, values of $\mu_{\Delta}$ smaller than 1 were obtained for some strengthening configurations, which means that these configurations have a detrimental influence in terms of deflection ductility performance. However, the displacement ductility augments with the increase of $\rho_{f}^{S}$, and values of $\mu_{\Delta}$ higher than 1 are obtained for the configurations with $\rho_{f}^{H}=0$. Therefore, a flexural strengthening strategy composed of CFRP laminates applied in both hogging and sagging regions does not significantly affect the original deflection ductility of the slab strips, providing a $\mu_{\Delta}$ ranging from 0.89 to 1.07 , which is in agreement with the experimental results obtained by Dalfré and Barros (2009a).

\subsection{Rotational Ductility Index}

The rotational ductility $(v)$ is defined as the ratio between the curvatures of the loaded section at the formation of the second and the first hinges $\left(v=\chi_{2 n d} / \chi_{1 s t}\right)$. The rotational ductility index $\left(\mu_{\chi}\right)$ is expressed as the ratio between the

rotational ductility of the strengthened $\left(v_{\text {streng }}\right)$ and the reference $\left(v_{\text {ref }}\right)$ slab strips $\left(\mu_{\chi}=v_{\text {streng }} / \nu_{\text {ref }}\right)$. The relationships $\mu_{\chi}-\rho_{s, e q}^{s}$ and $\mu_{\chi}-\rho_{s, e q}^{H}$ are represented in Figure 12, while the corresponding obtained values are included in Table 10. In this figure it is also indicated the relationships $\mu_{\chi}-\rho_{f}^{S}$ and $\mu_{\chi}-\rho_{f}^{H}$.

In the hogging region, the rotational ductility decreases with the increase of the percentage of the CFRP laminates in the hogging region. In fact, values of $\mu_{\chi}$ smaller than 1 were obtained for some strengthening configurations, which means that these configurations have a detrimental influence in terms of rotational ductility performance However, the rotational ductility augments with the increase of $\rho_{f}^{S}$, and values of $\mu_{\chi}$ higher than 1 are obtained for the configurations with $\rho_{f}^{H}=0$. In the slab strips strengthened in both sagging and hogging regions, $\mu_{\chi}<1$. Therefore, in the slab strips strengthened in the sagging and hogging regions, the strengthened sections show an average rotational ductility index of 0.49 , which means that the strengthened sections of a strengthened slab have a considerable lower rotational capacity than the corresponding sections of its reference slab. 


\subsection{Moment redistribution analysis}

The moment redistribution index (MRI) is defined as the ratio between the $\eta$ of a strengthened slab, $\eta_{\text {streng }}$, and the $\eta$ of its reference slab, $\eta_{\text {ref }},\left(M R I=\eta_{\text {streng }} / \eta_{\text {ref }}\right)$, where $\eta$ is the moment redistribution percentage at the formation of the second hinge (in the sagging region).

The relationships $M R I-\rho_{s, e q}^{S}$ and $M R I-\rho_{s, e q}^{H}$ are shown in Figure 13, while the corresponding obtained values are included in Table 10. In this figure it is also indicated the relationships $M R I-\rho_{f}^{S}$ and $M R I-\rho_{f}^{H}$.

It is observed that the MRI depends strongly on the strengthening arrangement. In the slab strips only strengthened in the hogging region $\eta_{\text {streng }}$ is less than $\eta_{r e f}$. Increasing the percentage of laminates in the sagging region, $M R I$ increases, regardless the $\rho_{s, e q}^{H}$. For slabs only strengthened in the sagging regions, MRI>1.0, which means that a strengthened slab has higher moment redistribution capacity than its reference slab. However, with the increase of the percentage of laminates in the hogging region, the $M R I$ decreases.

To avoid a decrease in the moment redistribution capacity, CFRP laminates strips should be applied in both sagging and hogging regions, in appropriate percentages. Figure 14 shows that the moment redistribution index increases with $\rho_{s, e q}^{s} / \rho_{s, e q}^{H}$. For $\rho_{s, e q}^{s} / \rho_{s, e q}^{H}>1.10$ the $M R I$ is positive.

\section{CONCLUSIONS}

This work explores the potentialities of the near surface mounted (NSM) CFRP laminates for the flexural strengthening of continuous reinforced concrete (RC) slabs, not only in terms of load carrying capacity, but also the moment redistribution and the ductility performance of this type of structures.

To evaluate the influence of the concrete strength class, the percentage of existing longitudinal tensile reinforcement and the percentage of CFRP on the strengthening effectiveness, moment redistribution capacity and ductility performance, a parametric study was carried out by executing material nonlinear analysis with a FEM-based computer program, which predictive performance was calibrated using the results of a previous experimental program. From the obtained results it can be pointed out the following main observations:

(i) The overall behavior of the strengthened slab strips is not significantly affected by the concrete strength class, as long as structural concrete strength classes, according the Model Code classification, are used;

(ii) The load carrying and the moment redistribution capacities strongly depend on the flexural strengthening arrangement; 
(iii) The load carrying capacity of the strengthened slabs increases with $\rho_{s, e q}^{S}$ and $\rho_{s, e q}^{H}$, but the increase is much more pronounced with $\rho_{s, e q}^{S}$, specially up to the formation of the plastic hinge in the hogging region ( $\rho_{s, e q}=A_{s l} / b d_{s}+\left(A_{f} E_{f} / E_{s}\right) /\left(b d_{f}\right)$ is the equivalent reinforcement ratio);

(vi) The moment redistribution decreases with the increase of $\rho_{s, e q}^{H}$, and increases with $\rho_{s, e q}^{S}$;

(v) The moment redistribution increases with $\rho_{s, e q}^{S} / \rho_{s, e q}^{H}$ and positive values (which means that the moment redistribution of the strengthened slab is higher than its corresponding reference slab) are only obtained for $\rho_{s, e q}^{S} / \rho_{s, e q}^{H}>1.10$;

(vi) A flexural strengthening strategy composed of CFRP laminates applied in both hogging and sagging regions does not significantly affect the deflection ductility performance of the unstrengthened RC slab;

(vii) The rotational capacity of the strengthened slab strips decreases with the increase of $\rho_{s, e q}^{H}$, and increases with $\rho_{s, e q}^{S}$. In the slab strips strengthened in both sagging and hogging regions, a considerable lower rotational capacity than its reference slabs was obtained.

The results evidence that the use of efficient strengthening strategies can provide adequate level of ductility and moment redistribution in statically indeterminate structures, with a considerable increase in the load carrying capacity.

\section{ACKNOWLEDGEMENTS}

The study reported in this thesis forms a part of the research program "CUTINEMO - Carbon fiber laminates applied according to the near surface mounted technique to increase the flexural resistance to negative moments of continuous reinforced concrete structures" supported by FCT, PTDC/ECM/73099/2006. The authors wish to acknowledge the support also provided by the S\&P and Casais. The first author also wishes to acknowledge the Erasmus Mobility Program between the University of Minho (Portugal) and the University of Ferrara (Italy), which allowed the real possibility of this international cooperation. The third author would like to acknowledge the National Council for Scientific and Technological Development (CNPq) - Brazil for financial support for scholarship (GDE 200953/2007-9).

\section{REFERENCES}

ACI Committee 318, “ACI 318-04 - Building code requirements for structural concrete and Commentary”, American Concrete Institute, Detroit, 2004. 
ACI Committee 440, "Design and Construction of Externally Bonded FRP Systems for Strengthening Concrete Structures (ACI 440.2R-08)," American Concrete Institute, Farmington Hills, MI, 2008.

Aiello, M.A., Valente, L. and Rizzo, A., "Moment redistribution in continuous reinforced concrete beams strengthened with carbon-fiber-reinforced polymer laminates", Mechanics of Composite Materials, 43(05), 453-466, September 2007.

Arduini, M., Tommaso, D. A., Nanni, A., "Brittle Failure in FRP Plate and Sheet Bonded Beams", ACI Structural, 94(4), 363-370, July 1, 1997.

Barros, J.A.O., Dalfré, G.M. and Dias, J.P., "Numerical Simulation of Continuous RC Slabs Strengthened using NSM Technique", Proceedings of 2nd International Conference on Concrete Repair, Rehabilitation and Retrofitting, Cape Town, South Africa, November 2008.

Barros, J.A.O.; Kotynia, R., "Possibilities and challenges of NSM for the flexural strengthening of RC structures", Fourth International Conference on FRP Composites in Civil Engineering (CICE2008), Zurich, Switzerland, 22-24July 2008.

Barros, J.A.O., Dias, S.J.E. and Lima, J.L.T., "Efficacy of CFRP-based techniques for the flexural and shear strengthening of concrete beams", Cement and Concrete Composites Journal, 29(3), 203-217, March 2007.

Barros, J.A.O., and Fortes, A.S., "Flexural strengthening of concrete beams with CFRP laminates bonded into slits", Cement and Concrete Composites Journal, 27(4), 471-480, April 2005.

Barros, J.A.O. and Figueiras, J.A., "Nonlinear analysis of steel fibre reinforced concrete slabs on grade”, Computers \& Structures Journal, 79(1), 97-106, 2001.

Bianco, V., Barros, J.A.O., Monti, G., "Bond model of NSM-CFRP in the context of the shear strengthening of RC beams", ASCE Journal of Structural Engineering, 135(6), 619-631, June 2009.

Blaschko, M., "Bond behaviour of CFRP strips glued into slits", Proceedings of the 6th International Symposium on Fiber Reinforced Polymer Reinforcement for Concrete Structures (Tan KH, ed.), FRPRCS6, Singapore, World Scientific, 2003.

Bonaldo, E. Composite materials and discrete steel fibres for the strengthening of thin concrete structures - NSM strengthening technique for double span continuous RC slabs, PhD Thesis, Department of Civil Engineering, University of Minho, Portugal, 2008.

Breveglieri, M., "Flexural strengthening of RC continuous slab strips using NSM CFRP laminates", MSc Thesis, University of Ferrara, Italy, 2009. 
Casadei, P., Nanni, A., Galati, N., Ibell, T., and Denton, S., "Moment redistribution in continuous CFRP strengthened concrete members: experimental results", International Conference Composites in Construction -CCC2003, Cosenza, Italy, 307-312, September 16-19 2003.

CEB-FIP Model Code 1990. (1993). Design Code. Thomas Telford, Lausanne, Switzerland.

Dalfré, G.M.; Barros, J.A.O., "Experimental and numerical analysis of RC two-span slabs strengthened with NSM CFRP laminates", FRPRCS10 - 10th International Symposium on Fiber Reinforced Polymer Reinforcement for Reinforced Concrete Structures, Tampa USA, April 2-4, $2011 \mathrm{~b}$.

Dalfré, G.M.; Barros, J.A.O., "Flexural strengthening of RC continuous slab strips using NSM CFRP laminates", Advances in Structural Engineering, 2011a (in press).

Dalfré, G.M.; Barros, J.A.O. - Movies of the SL15s25 slab of the second group of the NSM flexural strengthened continuous RC slabs. Available on the http://www.civil.uminho.pt/mrtest, 2009a.

Dalfré, G.M.; Barros, J.A.O., "Numerical analysis of two-way RC slabs flexural strengthened with NSM CFRP laminates", Technical report 09-DEC/E-09, Dep. Civil Eng., School Eng. University of Minho, 90 pags, June 2009 b.

De Lorenzis, .L, Nanni, A., "Bond between near surface mounted FRP rods and concrete in structural strengthening", ACI Structural Journal, 99(2), 123-33. March-April 2002.

El-Rafaie, S.A., Ashour, A.F. and Garrity, S.W., "Flexural strengthening of RC continuous beams using CFRP laminates", Cement and Concrete Composites Journal, 26, 765-775, 2004.

EN 1992-1-1, "Eurocode 2: Design of Concrete Structures-Part 1-1: General Rules and Rules for Buildings”, CEN, Brussels, December, 2004.

Liu, I.S.T., "Intermediate crack debonding of plated reinforced concrete beams", PhD Thesis, School of Civil and Environmental Engineering, The University of Adelaide, Adelaide, Australia, November 2005.

Liu, I.S.T., Ohlers, D.J. and Seracino, R., “Test on the Ductility of Reinforced Concrete Beams Retrofitted with FRP and Steel Near-Surface Mounted Plates”, Journal of Composites for Construction, 10(2), 106-114, March/April 2006.

Ohlers, D.J., Ju, G., Liu, I.S.T. and Seracino, R., "Moment redistribution in continuous plated RC flexural members. Part 1: neutral axis depth approach and tests", Engineering Structures, 26(14), 2197-2207, December 2004.

Ohlers, D.J., Ju, G., Liu, I.S.T. and Seracino, R., “A generic design approach for EB and NSM longitudinally plated RC beams" Construction and Building Materials 21, 697-708, 2007.

Rinaldi, Z., Coccia, S., Ianniruberto, U, "Redistribution of bending moment in continuous reinforced concrete beams strengthened with FRP”, ACI Structural Journal, 3(105), 318-326, May/June 2008.

Sena-Cruz, J.M., "Strengthening of concrete structures with near-surface mounted CFRP laminate strips", PhD Thesis, Department of Civil Engineering, University of Minho, http://www.civil.uminho.pt/composites, 2004. 
Sena-Cruz, J.M.; Barros, J.A.O., "Bond Between Near-Surface Mounted Carbon-Fiber-Reinforced Polymer Laminate Strips and Concrete”, Journal of Composites for Construction, 8(6), 519-527, 2004.

Sowa, L., Wasniewsk, T. and Kaminska, M E., "Discussion of the paper: Flexural strengthening of RC continuous beams using CFRP laminates [Cement and Concrete Composites 26, 765-775, 2004]", Cement and Concrete Composites Journal, 27(9-10), 958-961, October-November 2005.

Stevens, N. J., “Analytical modelling of reinforced concrete subjected to monotonic and reversed loadings”, Publication No. 87-1, ISBN 0-7727-7088-3, University of Toronto, January, 1987.

Spadea, G., Bencardino, F., Swamy, R.N., "Structural behaviour of composite RC beams with externally bonded CFRP”, Journal of Composites for Construction, 2(3), 132-7, August 1998.

Täljsten, B., Carolin, A., and Nordin, H., "Concrete structures strengthened with near surface mounted reinforcement of CFRP”, Advances in Structural Engineering, 6(3), 201-213, August 2003.

Vasseur, L., Matthys, S. and Taerwe, L., "Debonding mechanisms and moment redistribution of 2-span RC beams externally strengthened with FRP”, $8^{\text {th }}$ International Symposium on Fiber Reinforced Polymer Reinforcement for Concrete Structures - FRPRCS-8, University of Patras, Patras, Greece, 10 pp., July 2007. 


\section{LIST OF TABLE CAPTIONS}

Table 1 - Geometry, reinforcement and strengthening details of the cross sections of the slab strips.

Table 2 - Main results of the experimental program (Bonaldo, 2008).

Table 3 - Values of the parameters of the concrete constitutive model.

Table 4 - Values of the parameters of the steel constitutive model (see Figure 6).

Table 5- Resume of the strengthening arrangements (see Figure 9).

Table 6 - Concrete properties used for the FEM simulations.

Table 7 - Main results of the numerical simulations - concrete strength class C12/15.

Table 8 - Main results of the numerical simulations - concrete strength class C25/30.

Table 9 - Main results of the numerical simulations - concrete strength class C35/45.

Table 10 - Load carrying capacity, displacement ductility, rotational ductility and moment redistribution indexes. 
Table 1 - Geometry, reinforcement and strengthening details of the cross sections of the slab strips.

\begin{tabular}{|c|c|c|c|c|c|}
\hline$\eta$ & $\mathrm{M}^{-}$increasing & $\begin{array}{c}\text { Cross-Section } \\
\mathrm{S}_{1}-\mathrm{S}_{1}\end{array}$ & $\begin{array}{c}\text { Cross-Section } \\
\mathrm{S}_{2}-\mathrm{S}_{2}\end{array}$ & $\begin{array}{l}\text { Number of } \\
\text { CFRP } \\
\text { laminates } \\
\end{array}$ & $\begin{array}{l}\rho_{s, e q} \\
(\%)\end{array}$ \\
\hline \multirow{3}{*}{$15 \%$} & Reference & \multirow{3}{*}{$\begin{array}{c}A_{\mathrm{s}}^{\prime}=2 \phi 12 \mathrm{~mm} \\
\mathrm{~A}_{\mathrm{s}}=4 \phi 12 \mathrm{~mm}+3 \phi 8 \mathrm{~mm}\end{array}$} & \multirow{3}{*}{$\begin{array}{c}A_{s}=5 \phi 12 \mathrm{~mm} \\
A_{s}^{\prime}=2 \phi 12 \mathrm{~mm}+1 \phi 8 \mathrm{~mm}\end{array}$} & 0 & 1.60 \\
\hline & $25 \%$ & & & 3 & 1.68 \\
\hline & $50 \%$ & & & 7 & 1.78 \\
\hline \multirow{3}{*}{$30 \%$} & Reference & \multirow{3}{*}{$\begin{array}{c}\mathrm{A}_{\mathrm{s}}{ }^{\prime}=2 \phi 12 \mathrm{~mm} \\
\mathrm{~A}_{\mathrm{s}}=3 \phi 12 \mathrm{~mm}+4 \phi 10 \mathrm{~mm}\end{array}$} & \multirow{3}{*}{$\begin{array}{c}\mathrm{A}_{\mathrm{s}}=4 \phi 12 \mathrm{~mm} \\
\mathrm{~A}_{\mathrm{s}}^{\prime}=2 \phi 10 \mathrm{~mm}+1 \phi 12 \mathrm{~mm}\end{array}$} & 0 & 1.28 \\
\hline & $25 \%$ & & & 2 & 1.33 \\
\hline & $50 \%$ & & & 5 & 1.41 \\
\hline \multirow{3}{*}{$45 \%$} & Reference & \multirow{3}{*}{$\begin{array}{c}\mathrm{A}_{\mathrm{s}}^{\prime}=2 \phi 10 \mathrm{~mm} \\
\mathrm{~A}_{\mathrm{s}}=6 \phi 12 \mathrm{~mm}+1 \phi 8 \mathrm{~mm}\end{array}$} & \multirow{3}{*}{$\begin{array}{l}\mathrm{A}_{\mathrm{s}}=3 \phi 10 \mathrm{~mm}+2 \phi 8 \mathrm{~mm} \\
\mathrm{~A}_{\mathrm{s}}{ }^{\prime}=2 \phi 12 \mathrm{~mm}+1 \phi 8 \mathrm{~mm}\end{array}$} & 0 & 0.95 \\
\hline & $25 \%$ & & & 1 & 0.98 \\
\hline & $50 \%$ & & & 3 & 1.03 \\
\hline
\end{tabular}

Note: As'- compressive reinforcement, As - tensile reinforcement, CFRP laminates applied only in the hogging region. 
Table 2 - Main results of the experimental program (Bonaldo, 2008).

\begin{tabular}{|c|c|c|c|c|c|c|}
\hline $\begin{array}{c}\text { Slab } \\
\text { reference }\end{array}$ & $\begin{array}{c}\Delta F_{\text {Tar }} \\
(\%)\end{array}$ & $\begin{array}{l}\bar{F}_{\max } \\
(\mathrm{kN})\end{array}$ & $\begin{array}{c}R_{L, \bar{F} \max } \\
(\mathrm{kN})\end{array}$ & $\begin{array}{l}R_{C, \bar{F} \max } \\
(\mathrm{kN})\end{array}$ & $\begin{array}{c}M_{\text {Exp }}^{-} \\
\text {(kN.m) }\end{array}$ & $\begin{array}{c}\eta \\
(\%)\end{array}$ \\
\hline SL15 & - & 51.36 & 17.66 & 67.39 & 22.46 & 18.8 \\
\hline SL15S25 & 25 & $\begin{array}{c}57.60 \\
(12.15 \%) \\
\end{array}$ & 16.70 & 81.80 & $\begin{array}{c}33.88 \\
(50.84 \%) \\
\end{array}$ & 4.6 \\
\hline SL15S50 & 50 & $\begin{array}{c}62.36 \\
(21.42 \%) \\
\end{array}$ & 17.46 & 89.79 & $\begin{array}{c}38.42 \\
(71.06 \%) \\
\end{array}$ & 1.8 \\
\hline SL30 & - & 49.84 & 19.12 & 61.44 & 16.24 & 38.4 \\
\hline SL30S25 & 25 & $\begin{array}{c}54.87 \\
(10.09 \%) \\
\end{array}$ & 18.92 & 71.91 & $\begin{array}{c}23.84 \\
(46.80 \%) \\
\end{array}$ & 26.0 \\
\hline SL30S50 & 50 & $\begin{array}{c}58.09 \\
(16.55 \%) \\
\end{array}$ & 18.74 & 78.70 & $\begin{array}{c}28.85 \\
(77.64 \%) \\
\end{array}$ & 18.7 \\
\hline SL45 & - & 52.55 & 21.63 & 61.85 & 13.01 & 52.9 \\
\hline SL45S25 & 25 & $\begin{array}{c}54.49 \\
(3.69 \%) \\
\end{array}$ & 20.94 & 67.10 & $\begin{array}{c}17.65 \\
(35.66 \%) \\
\end{array}$ & 42.9 \\
\hline SL45S50 & 50 & $\begin{array}{c}57.79 \\
(9.97 \%)\end{array}$ & 20.82 & 73.94 & $\begin{array}{c}22.61 \\
(73.79 \%)\end{array}$ & 35.7 \\
\hline
\end{tabular}


Table 3 - Values of the parameters of the concrete constitutive model.

\begin{tabular}{|c|c|}
\hline Poisson's ratio & $v_{c}=0.15$ \\
\hline Initial Young's modulus & $E_{c}=28000 \mathrm{~N} / \mathrm{mm}^{2}$ \\
\hline Compressive strength & $f_{c}=40 \mathrm{~N} / \mathrm{mm}^{2}$ \\
\hline Strain at peak compression stress & $\varepsilon_{c l}=2.2 \times 10^{-3}$ \\
\hline Parameter defining the initial yield surface (Sena-Cruz 2004) & $\alpha_{0}=0.4$ \\
\hline Trilinear tension softening/stiffening diagram ${ }^{(1)}$ & $\begin{aligned} f_{c t} & =1.5 \mathrm{~N} / \mathrm{mm}^{2} ; G_{f}=0.05 \mathrm{~N} / \mathrm{mm} \\
\xi_{1} & =0.015 ; \alpha_{1}=0.6 ; \xi_{2}=0.2 ; \alpha_{2}=0.25\end{aligned}$ \\
\hline $\begin{array}{l}\text { Parameter defining the mode I fracture energy available to the new } \\
\text { crack (Sena-Cruz 2004) }\end{array}$ & $n=2$ \\
\hline Parameter for defining the shear retention factor (Sena-Cruz 2004) & $p_{1}=2$ \\
\hline Crack band-width, $l_{b}$ & $\begin{array}{l}\text { Square root of the area of Gauss } \\
\text { integration point }\end{array}$ \\
\hline Threshold angle (Sena-Cruz 2004) & $\alpha_{\mathrm{th}}=30^{\circ}$ \\
\hline Maximum number of cracks per integration point & 2 \\
\hline
\end{tabular}

${ }^{(1)} f_{c t}=\sigma_{n, 1}^{c r} ; \xi_{1}=\varepsilon_{n, 2}^{c r} / \varepsilon_{n, u}^{c r} ; \alpha_{1}=\sigma_{n, 2}^{c r} / \sigma_{n, 1}^{c r} ; \xi_{2}=\varepsilon_{n, 3}^{c r} / \varepsilon_{n, u}^{c r} ; \alpha_{2}=\sigma_{n, 3}^{c r} / \sigma_{n, 1}^{c r}$ (see Figure 5) 
Table 4 -Values of the parameters of the steel constitutive model (see Figure 6).

\begin{tabular}{ccccc}
\hline $\begin{array}{l}\text { Steel bar } \\
\text { diameter }\end{array}$ & $\mathrm{P}_{1}\left(\varepsilon_{\mathrm{sy}}[-] ; \sigma_{\mathrm{sy}}[\mathrm{MPa}]\right)$ & $\mathrm{P}_{2}\left(\varepsilon_{\mathrm{sh}}[-] ; \sigma_{\mathrm{sh}}[\mathrm{MPa}]\right)$ & $\mathrm{P}_{3}\left(\varepsilon_{\mathrm{su}}[-] ; \sigma_{\mathrm{su}}[\mathrm{MPa}]\right)$ & $\mathrm{E}_{\mathrm{s}}[\mathrm{GPa}]$ \\
\hline$\varnothing 8 \mathrm{~mm}$ & $\left(1.90 \times 10^{-3} ; 379.16\right)$ & $\left(4.42 \times 10^{-2} ; 512.19\right)$ & $\left(8.85 \times 10^{-2} ; 541.66\right)$ & 200.80 \\
\hline$\varnothing 10 \mathrm{~mm}$ & $\left(2.32 \times 10^{-3} ; 413.20\right)$ & $\left(3.07 \times 10^{-2} ; 434.75\right)$ & $\left(1.31 \times 10^{-1} ; 546.25\right)$ & 178.24 \\
\hline$\varnothing 12 \mathrm{~mm}$ & $\left(2.09 \times 10^{-3} ; 414.35\right)$ & $\left(3.05 \times 10^{-2} ; 435.63\right)$ & $\left(1.02 \times 10^{-1} ; 537.98\right)$ & 198.36 \\
\hline
\end{tabular}


Table 5- Resume of the strengthening arrangements (see Figure 9).

\begin{tabular}{|c|c|c|c|c|c|}
\hline \multirow{2}{*}{$\begin{array}{c}\text { Concrete } \\
\text { strength } \\
\text { class }\end{array}$} & \multicolumn{2}{|c|}{ Number of laminates } & \multirow{2}{*}{$\begin{array}{l}\rho_{s, e q}^{S} \\
(\%)\end{array}$} & \multirow{2}{*}{$\begin{array}{l}\rho_{s, e q}^{H} \\
(\%)\end{array}$} & \multirow{2}{*}{$\begin{array}{l}\text { F.E.M. } \\
\text { ID }\end{array}$} \\
\hline & $S^{(a)}$ & $\mathrm{H}^{(\mathrm{b})}$ & & & \\
\hline \multirow[t]{9}{*}{ C12/15 } & 0 & 0 & 1.71 & 1.60 & SL15_15 ${ }^{(\mathrm{c})}$ \\
\hline & 0 & 2 & 1.71 & 1.71 & SL15_15_0_2 \\
\hline & 0 & 4 & 1.71 & 1.82 & SL15_15_0_4 \\
\hline & 2 & 0 & 1.82 & 1.60 & SL15_15_2_0 \\
\hline & 4 & 0 & 1.92 & 1.60 & SL15_15_4_0 \\
\hline & 2 & 2 & 1.82 & 1.71 & SL15_15_2_2 \\
\hline & 2 & 4 & 1.82 & 1.82 & SL15_15_2_4 \\
\hline & 4 & 2 & 1.92 & 1.71 & SL15_15_4_2 \\
\hline & 4 & 4 & 1.92 & 1.82 & SL15_15_4_4 \\
\hline \multirow[t]{9}{*}{$\mathrm{C} 25 / 30$} & 0 & 0 & 1.71 & 1.60 & SL15_30 ${ }^{(c)}$ \\
\hline & 0 & 2 & 1.71 & 1.71 & SL15_30_0_2 \\
\hline & 0 & 4 & 1.71 & 1.82 & SL15_30_0_4 \\
\hline & 2 & 0 & 1.82 & 1.60 & SL15_30_2_0 \\
\hline & 4 & 0 & 1.92 & 1.60 & SL15_30_4_0 \\
\hline & 2 & 2 & 1.82 & 1.71 & SL15_30_2_4 \\
\hline & 2 & 4 & 1.82 & 1.82 & SL15_30_2_4 \\
\hline & 4 & 2 & 1.92 & 1.71 & SL15_30_4_2 \\
\hline & 4 & 4 & 1.92 & 1.82 & SL15_30_4_4 \\
\hline \multirow[t]{9}{*}{ C35/45 } & 0 & 0 & 1.71 & 1.60 & SL15_45 ${ }^{(\mathrm{c})}$ \\
\hline & 0 & 2 & 1.71 & 1.71 & SL15_45_0_2 \\
\hline & 0 & 4 & 1.71 & 1.82 & SL15_45_0_4 \\
\hline & 2 & 0 & 1.82 & 1.60 & SL15_45_2_0 \\
\hline & 4 & 0 & 1.92 & 1.60 & SL15_45_4_0 \\
\hline & 2 & 2 & 1.82 & 1.71 & SL15_45_2_2 \\
\hline & 2 & 4 & 1.82 & 1.82 & SL15_45_2_4 \\
\hline & 4 & 2 & 1.92 & 1.71 & SL15_45_4_2 \\
\hline & 4 & 4 & 1.92 & 1.82 & SL15_45_4_4 \\
\hline
\end{tabular}


Table 6 - Concrete properties used for the FEM simulations.

\begin{tabular}{|c|c|c|c|}
\hline & $\mathrm{C} 12 / 15$ & $\mathrm{C} 25 / 30$ & $\mathrm{C} 35 / 45$ \\
\hline Compressive strength & $\mathrm{f}_{\mathrm{cm}}=20 \mathrm{~N} / \mathrm{mm}^{2}$ & $\mathrm{f}_{\mathrm{cm}}=33 \mathrm{~N} / \mathrm{mm}^{2}$ & $\mathrm{f}_{\mathrm{cm}}=43 \mathrm{~N} / \mathrm{mm}^{2}$ \\
\hline Initial Young's modulus & $\mathrm{E}_{\mathrm{c}}=22.95 \mathrm{~N} / \mathrm{mm}^{2}$ & $\mathrm{E}_{\mathrm{c}}=26.4 \mathrm{~N} / \mathrm{mm}^{2}$ & $\mathrm{E}_{\mathrm{c}}=28.9 \mathrm{~N} / \mathrm{mm}^{2}$ \\
\hline Poisson's ratio & \multicolumn{3}{|c|}{$v_{c}=0.15$} \\
\hline Strain at peak compression stress & $\varepsilon_{\mathrm{c} 1}=1.8 \times 10^{-3}$ & $\varepsilon_{\mathrm{c} 1}=2.1 \times 10^{-3}$ & $\varepsilon_{\mathrm{c} 1}=2.25 \times 10^{-3}$ \\
\hline \multirow[t]{2}{*}{$\begin{array}{l}\text { Tri-linear tension } \\
\text { softening/stiffening diagram }\end{array}$} & $\begin{aligned} \mathrm{f}_{\mathrm{ct}} & =1.05 \mathrm{~N} / \mathrm{mm}^{2} \\
\mathrm{G}_{\mathrm{f}} & =0.041 \mathrm{~N} / \mathrm{mm}^{2}\end{aligned}$ & $\begin{array}{l}\mathrm{f}_{\mathrm{ct}}=1.71 \mathrm{~N} / \mathrm{mm}^{2} \\
\mathrm{G}_{\mathrm{f}}=0.058 \mathrm{~N} / \mathrm{mm}\end{array}$ & $\begin{array}{l}\mathrm{f}_{\mathrm{ct}}=2.14 \mathrm{~N} / \mathrm{mm}^{2} \\
\mathrm{G}_{\mathrm{f}}=0.07 \mathrm{~N} / \mathrm{mm}\end{array}$ \\
\hline & \multicolumn{3}{|c|}{$\xi_{1}=0.015 ; \alpha_{1}=0.6 ; \xi_{2}=0.2 ; \alpha_{2}=0.25$} \\
\hline \multicolumn{2}{|c|}{ Parameter defining the initial yield surface } & \multicolumn{2}{|c|}{$\alpha_{0}=0.4$} \\
\hline \multicolumn{3}{|c|}{ Parameter defining the mode I fracture energy to the new crack } & $\mathrm{n}=2$ \\
\hline \multicolumn{2}{|c|}{ Parameter to define the evolution of the shear retention factor } & \multicolumn{2}{|c|}{$\mathrm{p}_{1}=2$} \\
\hline \multicolumn{2}{|c|}{ Crack band-width } & \multicolumn{2}{|c|}{$\begin{array}{l}\text { Square root of the area of Gauss } \\
\text { integration point }\end{array}$} \\
\hline \multicolumn{2}{|c|}{ Threshold angle (Sena-Cruz 2004) } & \multicolumn{2}{|c|}{$\alpha_{\mathrm{th}}=30^{\circ}$} \\
\hline \multicolumn{2}{|c|}{ Maximum numbers of cracks per integration point } & \multicolumn{2}{|r|}{2} \\
\hline
\end{tabular}


Table 7 - Main results of the numerical simulations - concrete strength class C12/15.

\begin{tabular}{|c|c|c|c|c|c|c|c|c|c|c|c|c|c|c|c|c|c|}
\hline \multirow{2}{*}{$\begin{array}{c}\text { Concrete } \\
\text { strenght class } \\
\text { C12/15 }\end{array}$} & \multirow[b]{2}{*}{$\begin{array}{c}F_{y}^{H} \\
(\mathrm{kN})\end{array}$} & \multicolumn{7}{|c|}{ Hinge in the Hogging region $(\mathrm{H})$} & \multicolumn{6}{|c|}{ Hinge in the Sagging region (S) } & \multirow[b]{2}{*}{$\begin{array}{c}\mathcal{E}_{s}^{S} \\
(\% o)\end{array}$} & \multirow[b]{2}{*}{$\begin{array}{c}\mathcal{E}_{f}^{S} \\
(\% o)\end{array}$} & \multirow[b]{2}{*}{$\begin{array}{c}\eta \\
(\%)\end{array}$} \\
\hline & & $\begin{array}{c}\Delta_{y}^{H} \\
(\mathrm{~mm})\end{array}$ & $\begin{array}{c}\varepsilon_{c}^{H} \\
(\% \circ)\end{array}$ & $\begin{array}{l}\varepsilon_{s}^{H} \\
(\% o)\end{array}$ & $\begin{array}{c}\varepsilon_{f}^{H} \\
(\% o)\end{array}$ & $\begin{array}{c}\mathcal{E}_{c}^{S} \\
(\% o)\end{array}$ & $\begin{array}{c}\varepsilon_{s}^{S} \\
(\% o)\end{array}$ & $\begin{array}{c}\mathcal{E}_{f}^{S} \\
(\% o)\end{array}$ & $\begin{array}{c}F_{y}^{S} \\
(\mathrm{kN})\end{array}$ & $\begin{array}{c}\Delta_{y}^{S} \\
(\mathrm{~mm})\end{array}$ & $\begin{array}{l}\varepsilon_{c}^{H} \\
(\% o)\end{array}$ & $\begin{array}{l}\varepsilon_{s}^{H} \\
(\% o)\end{array}$ & $\begin{array}{l}\varepsilon_{f}^{H} \\
(\% o)\end{array}$ & $\begin{array}{l}\mathcal{E}_{c}^{S} \\
(\% o)\end{array}$ & & & \\
\hline Reference & 36.69 & 14.01 & -1.45 & 2.09 & -- & -1.20 & 1.66 & -- & 41.97 & 18.27 & -3.64 & 10.10 & -- & -1.54 & 2.10 & -- & 10.65 \\
\hline SL15_15_0_2 & 39.44 & 14.76 & -1.54 & 2.08 & 2.68 & -1.29 & 1.76 & -- & 44.32 & 17.33 & -2.13 & 3.64 & 4.59 & -1.53 & 2.09 & -- & 0.96 \\
\hline SL15_15_0_4 & 42.70 & 15.72 & -1.65 & 2.09 & 2.69 & -1.39 & 1.89 & -- & 45.50 & 17.03 & -1.90 & 2.59 & 3.33 & -1.53 & 2.09 & -- & -2.99 \\
\hline SL15_15_2_0 & 37.61 & 13.71 & -1.45 & 2.09 & -- & -1.18 & 1.55 & 1.99 & 45.20 & 19.57 & -4.59 & 13.25 & -- & -1.64 & 2.09 & 2.70 & 16.15 \\
\hline SL15_15_2_2 & 40.83 & 14.61 & -1.56 & 2.09 & 2.70 & -1.29 & 1.66 & 2.14 & 48.08 & 18.45 & -2.42 & 4.47 & 5.61 & -1.64 & 2.09 & 2.70 & 5.09 \\
\hline SL15_15_2_4 & 43.94 & 15.47 & -1.66 & 2.09 & 2.71 & -1.38 & 1.78 & 2.29 & 49.49 & 18.05 & -2.15 & 3.14 & 4.01 & -1.64 & 2.09 & 2.70 & 0.45 \\
\hline SL15_15_4_0 & 37.61 & 13.17 & -1.42 & 2.09 & -- & -1.14 & 1.42 & 2.28 & 48.27 & 21.02 & -5.79 & 17.62 & -- & -1.76 & 2.10 & 2.97 & 22.09 \\
\hline SL15_15_4_2 & 41.72 & 14.34 & -1.55 & 2.09 & 2.69 & -1.27 & 1.56 & 2.02 & 51.72 & 19.60 & -2.70 & 5.24 & 6.54 & -1.75 & 2.09 & 2.72 & 8.81 \\
\hline SL15_15_4_4 & 44.86 & 15.17 & -1.65 & 2.09 & 2.70 & -1.37 & 1.67 & 2.17 & 53.39 & 19.07 & -2.38 & 3.68 & 4.68 & -1.75 & 2.09 & 2.73 & 3.65 \\
\hline
\end{tabular}


Table 8 - Main results of the numerical simulations - concrete strength class C25/30.

\begin{tabular}{|c|c|c|c|c|c|c|c|c|c|c|c|c|c|c|c|c|c|}
\hline \multirow{2}{*}{$\begin{array}{c}\text { Concrete } \\
\text { strenght class } \\
\mathrm{C} 25 / 30\end{array}$} & \multirow[b]{2}{*}{$\begin{array}{c}F_{y}^{H} \\
(\mathrm{kN})\end{array}$} & \multicolumn{7}{|c|}{ Hinge in the Hogging region $(\mathrm{H})$} & \multicolumn{6}{|c|}{ Hinge in the Sagging region (S) } & \multirow[b]{2}{*}{$\begin{array}{c}\mathcal{E}_{s}^{S} \\
(\% o)\end{array}$} & \multirow[b]{2}{*}{$\begin{array}{c}\mathcal{E}_{f}^{S} \\
(\% o)\end{array}$} & \multirow[b]{2}{*}{$\begin{array}{c}\eta \\
(\%)\end{array}$} \\
\hline & & $\begin{array}{c}\Delta_{y}^{H} \\
(\mathrm{~mm})\end{array}$ & $\begin{array}{c}\varepsilon_{c}^{H} \\
(\% o)\end{array}$ & $\begin{array}{l}\varepsilon_{s}^{H} \\
(\% o)\end{array}$ & $\begin{array}{c}\varepsilon_{f}^{H} \\
(\% o)\end{array}$ & $\begin{array}{c}\mathcal{E}_{c}^{S} \\
(\% o)\end{array}$ & $\begin{array}{c}\varepsilon_{s}^{S} \\
(\% o)\end{array}$ & $\begin{array}{c}\mathcal{E}_{f}^{S} \\
(\% o)\end{array}$ & $\begin{array}{c}F_{y}^{S} \\
(\mathrm{kN})\end{array}$ & $\begin{array}{c}\Delta_{y}^{S} \\
(\mathrm{~mm})\end{array}$ & $\begin{array}{l}\varepsilon_{c}^{H} \\
(\% o)\end{array}$ & $\begin{array}{l}\varepsilon_{s}^{H} \\
(\% o)\end{array}$ & $\begin{array}{l}\varepsilon_{f}^{H} \\
(\% o)\end{array}$ & $\begin{array}{l}\mathcal{E}_{c}^{S} \\
(\% o)\end{array}$ & & & \\
\hline Reference & 37.63 & 13.07 & -1.23 & 2.09 & -- & -1.02 & 1.61 & -- & 43.95 & 17.23 & -2.87 & 9.32 & -- & -1.31 & 2.09 & -- & 9.87 \\
\hline SL15_30_0_2 & 41.53 & 14.17 & -1.34 & 2.09 & 2.65 & -1.12 & 1.76 & -- & 46.50 & 16.56 & -1.82 & 3.70 & 4.61 & -1.31 & 2.09 & -- & 1.11 \\
\hline SL15_30_0_4 & 44.78 & 15.01 & -1.43 & 2.09 & 2.67 & -1.20 & 1.88 & -- & 47.67 & 16.24 & -1.63 & 2.65 & 3.36 & -1.32 & 2.09 & -- & -2.85 \\
\hline SL15_30_2_0 & 38.86 & 12.91 & -1.23 & 2.08 & -- & -1.02 & 1.59 & 1.94 & 47.70 & 18.66 & -3.69 & 12.62 & -- & -1.41 & 2.10 & 2.67 & 14.46 \\
\hline SL15_30_2_2 & 42.58 & 13.88 & -1.34 & 2.09 & 2.65 & -1.11 & 1.65 & 2.11 & 50.37 & 17.59 & -2.06 & 4.44 & 5.51 & -1.40 & 2.09 & 2.66 & 5.19 \\
\hline SL15_30_2_4 & 45.90 & 14.71 & -1.43 & 2.09 & 2.67 & -1.19 & 1.77 & 2.25 & 51.87 & 17.23 & -1.84 & 3.25 & 4.09 & -1.41 & 2.09 & 2.66 & 0.61 \\
\hline SL15_30_4_0 & 40.18 & 12.70 & -1.24 & 2.09 & -- & -1.02 & 1.45 & 1.86 & 50.93 & 19.82 & -4.50 & 15.79 & 0.00 & -1.49 & 2.10 & 2.68 & 20.54 \\
\hline SL15_30_4_2 & 42.87 & 13.42 & -1.32 & 2.09 & 2.65 & -1.08 & 1.53 & 1.96 & 53.91 & 18.48 & -2.26 & 5.12 & 6.33 & -1.49 & 2.09 & 2.68 & 8.71 \\
\hline SL15_30_4_4 & 46.91 & 14.45 & -1.43 & 2.09 & 2.67 & -1.18 & 1.67 & 2.13 & 55.87 & 18.16 & -2.02 & 3.76 & 4.71 & -1.49 & 2.09 & 2.68 & 3.83 \\
\hline
\end{tabular}


Table 9 - Main results of the numerical simulations - concrete strength class C35/45.

\section{Concrete}

strenght class

Hinge in the Hogging region $(\mathrm{H})$

Hinge in the Sagging region $(\mathrm{S})$

\begin{tabular}{|c|c|c|c|c|c|c|c|c|c|c|c|c|c|c|c|c|c|}
\hline 5 & $\begin{array}{c}F_{y}^{H} \\
(\mathrm{kN})\end{array}$ & $\begin{array}{c}\Delta_{y}^{H} \\
(\mathrm{~mm})\end{array}$ & $\begin{array}{c}\mathcal{E}_{c}^{H} \\
(\% o)\end{array}$ & $\begin{array}{c}\mathcal{E}_{s}^{H} \\
(\% o)\end{array}$ & $\begin{array}{c}\varepsilon_{f}^{H} \\
(\% o)\end{array}$ & $\begin{array}{c}\mathcal{E}_{c}^{S} \\
(\% o)\end{array}$ & $\begin{array}{c}\mathcal{E}_{s}^{S} \\
(\% o)\end{array}$ & $\begin{array}{c}\mathcal{E}_{f}^{S} \\
(\% o)\end{array}$ & $\begin{array}{c}F_{y}^{S} \\
(\mathrm{kN})\end{array}$ & $\begin{array}{c}\Delta_{y}^{S} \\
(\mathrm{~mm})\end{array}$ & $\begin{array}{l}\varepsilon_{c}^{H} \\
(\% o)\end{array}$ & $\begin{array}{l}\varepsilon_{s}^{H} \\
(\% o)\end{array}$ & $\begin{array}{l}\mathcal{E}_{f}^{H} \\
(\% o)\end{array}$ & $\begin{array}{l}\mathcal{E}_{c}^{S} \\
(\% o)\end{array}$ & $\begin{array}{c}\mathcal{E}_{s}^{S} \\
(\% o)\end{array}$ & $\begin{array}{c}\mathcal{E}_{f}^{S} \\
(\% o)\end{array}$ & $\begin{array}{c}\eta \\
(\%)\end{array}$ \\
\hline Refe & 39.05 & 12.90 & -1.15 & 2.09 & & -9.70 & 1.65 & -- & 44.53 & 16.60 & -2.42 & 8.71 & & 1.19 & 2.09 & -- & 9.30 \\
\hline L15 & 2.23 & 13.73 & -1.23 & 2.09 & 2.64 & -1.04 & 1.76 & -- & 47.30 & 16.06 & -1.66 & 3.69 & 4.57 & -1.20 & 2.10 & -- & 1.13 \\
\hline SL 15 & 5.46 & 14.52 & -1.31 & 2.09 & 2.65 & -1.10 & 1.88 & -- & 48.29 & 15.67 & -1.47 & 2.61 & 3.29 & -1.20 & 2.09 & -- & -2.89 \\
\hline SL1 & 40.04 & 12.70 & -1.15 & 2.09 & -- & -0.97 & 1.53 & 1.94 & 48.61 & 18.02 & -3.07 & 12.10 & -- & -1.29 & 2.09 & 2.64 & 15.02 \\
\hline & 2.69 & 13.26 & -1.22 & 2.10 & 2.65 & -1.02 & 1.6 & 2.05 & 51.38 & 17 & -1.86 & 4.46 & 5.5 & -1.29 & 2.09 & 2.62 & 5.35 \\
\hline & 46.39 & 14.16 & -1.31 & 2.09 & 2.65 & -1.10 & 1.74 & 2.21 & 52.88 & 16.74 & -1.68 & 3.28 & 4.10 & -1.29 & 2.09 & 2.65 & 0.72 \\
\hline & 41.06 & 12.51 & -1.15 & 2.09 & -- & -0.96 & 1.45 & 1.85 & 52.09 & 19.19 & -3.56 & 14.38 & -- & -1.37 & 2.08 & 2.65 & 20.15 \\
\hline & 3.98 & 13.13 & -1.22 & 2.10 & 2.65 & -1.02 & 1.54 & 1.96 & 55.41 & 18.16 & -2.05 & 5.26 & 6.4 & -1.38 & 2.09 & 2.66 & 9.05 \\
\hline L15_ & 7.73 & 14.01 & -1.31 & 2.08 & 2.64 & -1.10 & 1.66 & 2.11 & 57.14 & 17.71 & -1.85 & 3.81 & 4.75 & -1.38 & 2.09 & 2.65 & 3.94 \\
\hline
\end{tabular}


Table 10 - Load carrying capacity, displacement ductility, rotational ductility and moment redistribution indexes.

\begin{tabular}{|c|c|c|c|c|c|c|c|c|c|c|c|c|}
\hline \multirow{2}{*}{ Slab Strip ID } & \multicolumn{4}{|c|}{ C12/15 } & \multicolumn{4}{|c|}{$\mathrm{C25} / 30$} & \multicolumn{4}{|c|}{ C35/45 } \\
\hline & $\lambda$ & $\mu_{\Delta}$ & $\mu_{\chi}$ & MRI & $\lambda$ & $\mu_{\Delta}$ & $\mu_{\chi}$ & MRI & $\lambda$ & $\mu_{\Delta}$ & $\mu_{\chi}$ & MRI \\
\hline Reference & 1.00 & 1.00 & 1.00 & 1.00 & 1.00 & 1.00 & 1.00 & 1.00 & 1.00 & 1.00 & 1.00 & 1.00 \\
\hline SL15_0_2 & 1.06 & 0.90 & 0.41 & 0.09 & 1.06 & 0.89 & 0.44 & 0.11 & 1.06 & 0.91 & 0.47 & 0.12 \\
\hline SL15_0_4 & 1.08 & 0.83 & 0.31 & -0.28 & 1.08 & 0.82 & 0.33 & -0.29 & 1.08 & 0.84 & 0.35 & -0.31 \\
\hline SL15_2_0 & 1.08 & 1.09 & 1.30 & 1.52 & 1.09 & 1.10 & 1.34 & 1.46 & 1.09 & 1.10 & 1.36 & 1.62 \\
\hline SL15_2_2 & 1.15 & 0.97 & 0.49 & 0.48 & 1.15 & 0.96 & 0.52 & 0.53 & 1.15 & 1.00 & 0.56 & 0.58 \\
\hline SL15_2_4 & 1.18 & 0.89 & 0.36 & 0.04 & 1.18 & 0.89 & 0.39 & 0.06 & 1.19 & 0.92 & 0.42 & 0.08 \\
\hline SL15_4_0 & 1.15 & 1.21 & 1.72 & 2.07 & 1.16 & 1.18 & 1.65 & 2.08 & 1.17 & 1.19 & 1.61 & 2.17 \\
\hline SL15_4_2 & 1.23 & 1.05 & 0.56 & 0.83 & 1.23 & 1.05 & 0.59 & 0.88 & 1.24 & 1.07 & 0.64 & 0.97 \\
\hline SL15_4_4 & 1.27 & 0.96 & 0.42 & 0.34 & 1.27 & 0.95 & 0.45 & 0.39 & 1.28 & 0.98 & 0.49 & 0.42 \\
\hline
\end{tabular}




\section{LIST OF FIGURE CAPTIONS}

Figure 1 - Characteristics of the slab specimens: (a) longitudinal view of the reinforcement arrangements; reinforcement and strengthening details of the (b) SL15, (c) SL30, and (d) SL45 series; (e) geometry of the slit and CFRP strip (A $A_{s}^{\prime}$ top reinforcement; As - bottom reinforcement; dimensions in mm).

Figure 2 - Force versus deflection at the loaded sections for the SL15 series.

Figure 3 - Degree of moment redistribution, $\eta$, for the slab strips of SL15 series.

Figure 4 - Finite element mesh adopted to discretize the half part of a RC slab.

Figure 5 - Crack normal stress $v s$ crack normal strain diagram for modeling the concrete tensile-softening behavior. Figure 6 - Uniaxial constitutive model of the steel bars.

Figure 7 - Force-deflection relationship for the slabs: (a) SL15, (b) SL15s25 and (c) SL15s50.

Figure 8 - SL15s50: (a) load - steel strain at slab loaded sections, (b) load - concrete strain at loaded sections and (c) load - CFRP laminate strain.

Figure 9 - Strengthening arrangements: NSM CFRP laminates applied in the (a) hogging region, (b) sagging region and (c) sagging and hogging regions (dimensions in $\mathrm{mm}$ ).

Figure 10 - Relationship between the load carrying capacity index and the equivalent reinforcement ratio in the (a) sagging and (b) hogging regions.

Figure 11 - Relationship between the displacement ductility index and the equivalent reinforcement ratio in the (a) sagging and (b) hogging regions.

Figure 12 - Relationship between the rotational ductility index and the equivalent reinforcement ratio in the (a) sagging and (b) hogging regions.

Figure 13 - Relationship between the moment redistribution index and the equivalent reinforcement ratio in the (a) sagging and (b) hogging regions.

Figure 14 - Relationship between the moment redistribution index and $\rho_{s, e q}^{S} / \rho_{s, e q}^{H}$ 


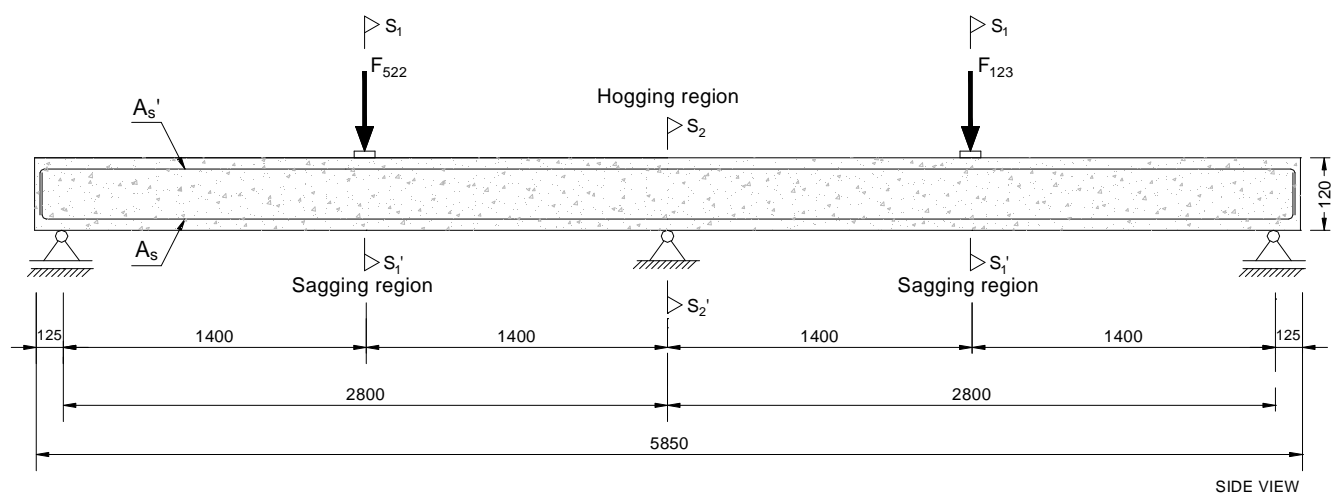

(a)

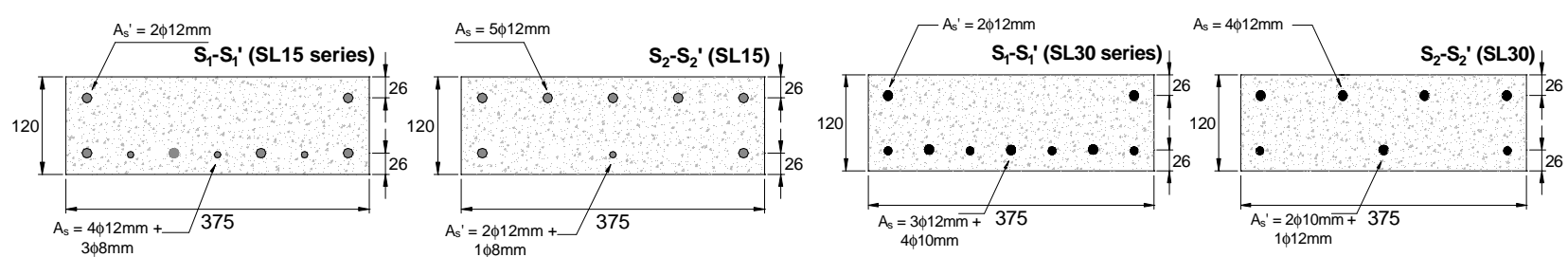

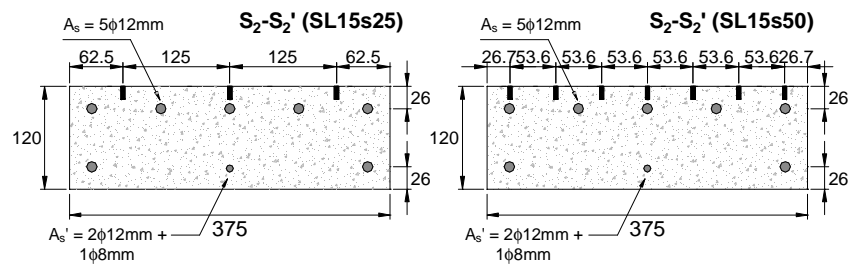

(b)
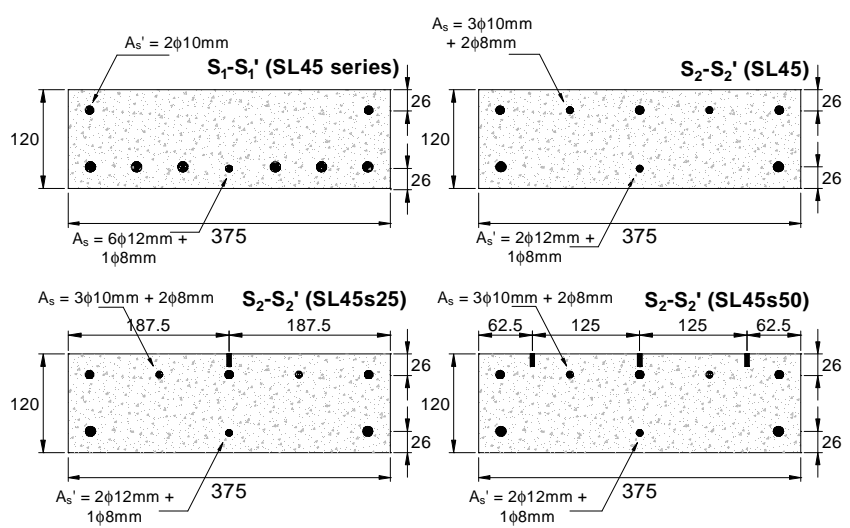

(d)

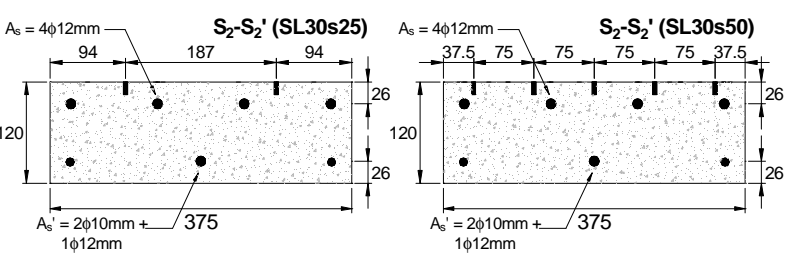

(c)

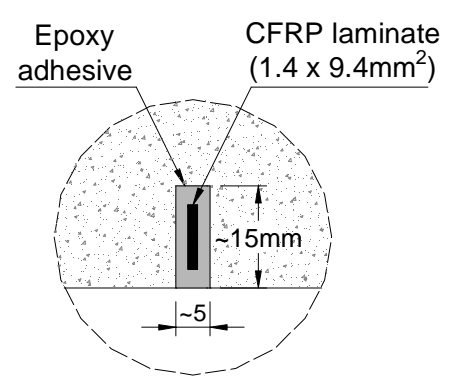

(e)

Figure 1 - Characteristics of the slab specimens: (a) longitudinal view of the reinforcement arrangements; reinforcement and strengthening details of the (b) SL15, (c) SL30, and (d) SL45 series; (e) geometry of the slit and CFRP strip ( $A_{s}^{\prime}$ top reinforcement; $A_{s}$ - bottom reinforcement; dimensions in $\mathrm{mm}$ ). 


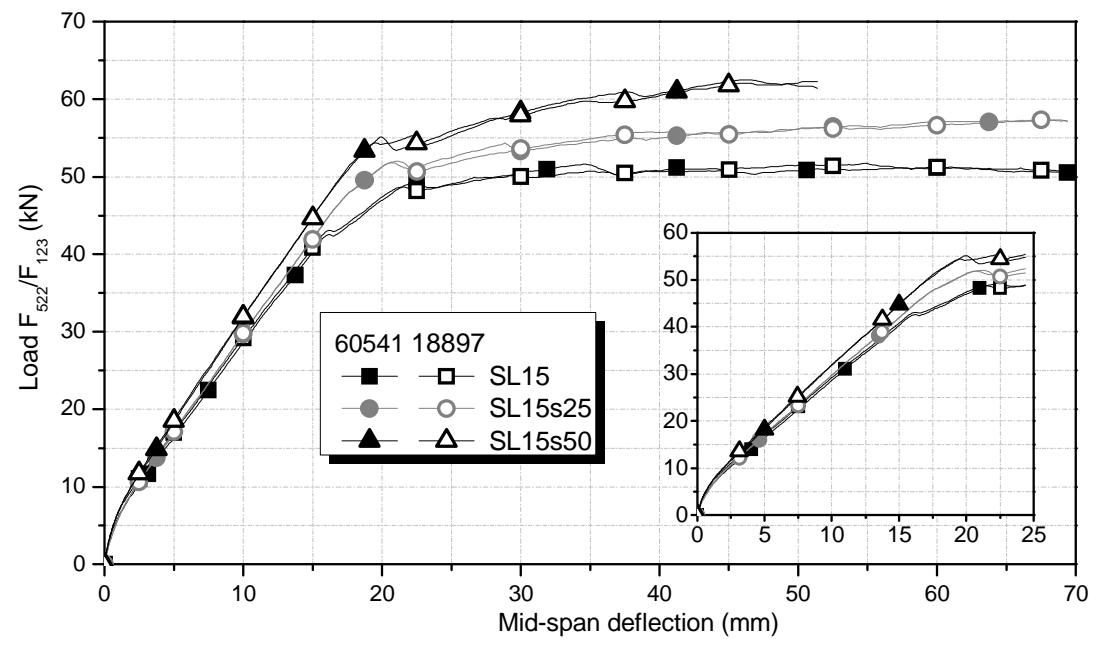

Figure 2 - Force versus deflection at the loaded sections for the SL15 series. 


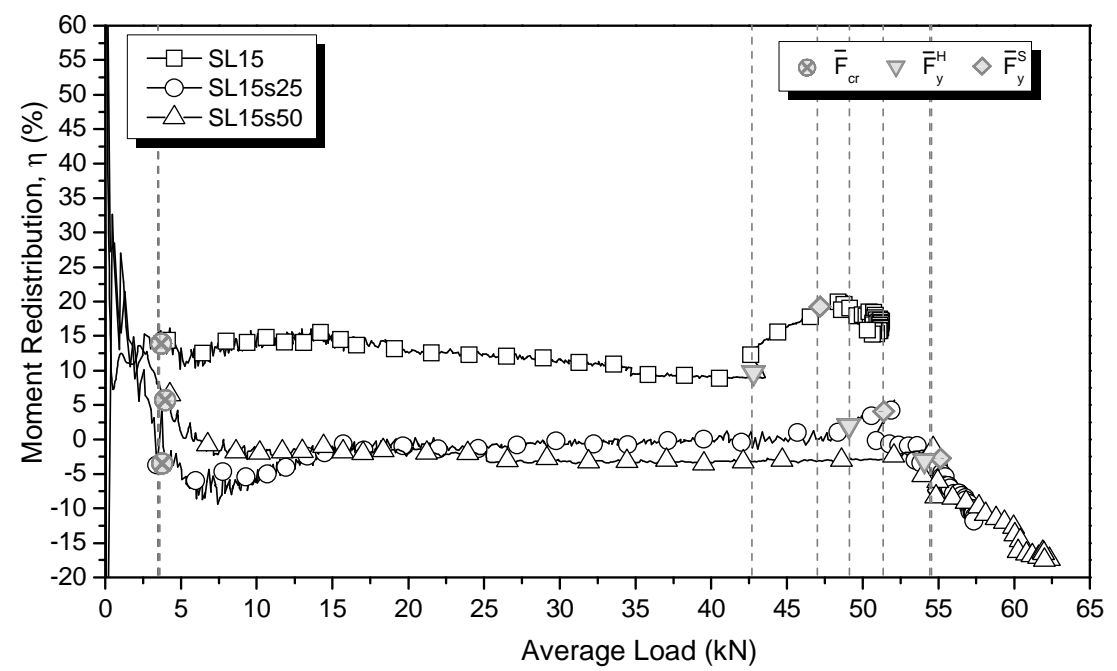

Figure 3 - Degree of moment redistribution, $\eta$, for the slab strips of SL15 series. 


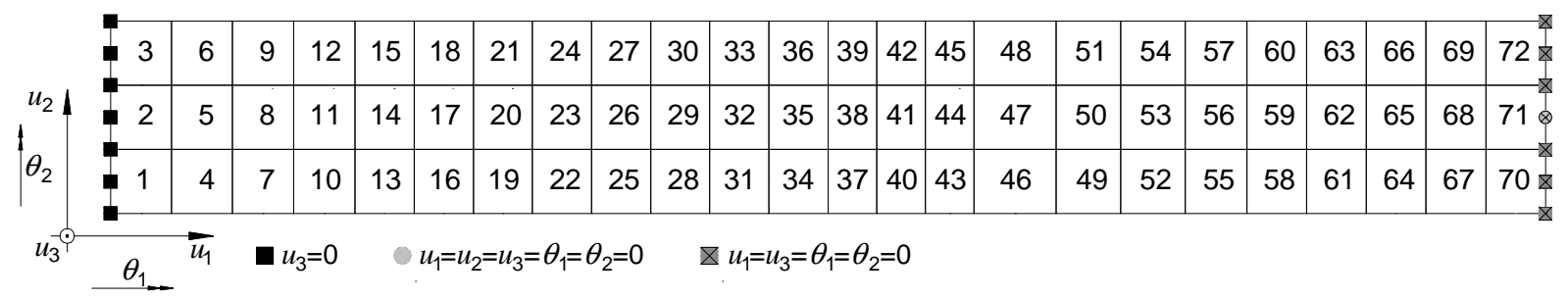

Figure 4 - Finite element mesh adopted to discretize the half part of a RC slab. 


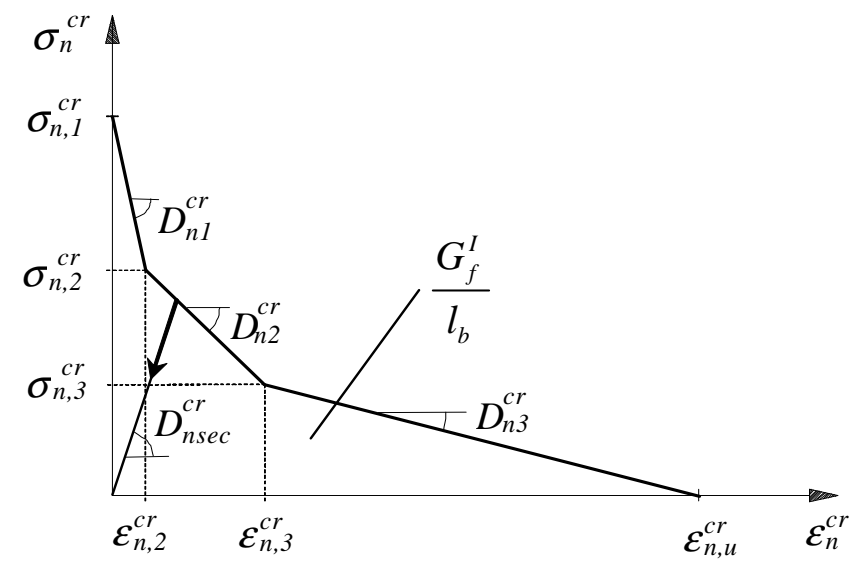

Figure 5 - Crack normal stress $v s$ crack normal strain diagram for modeling the concrete tensile-softening behavior. 


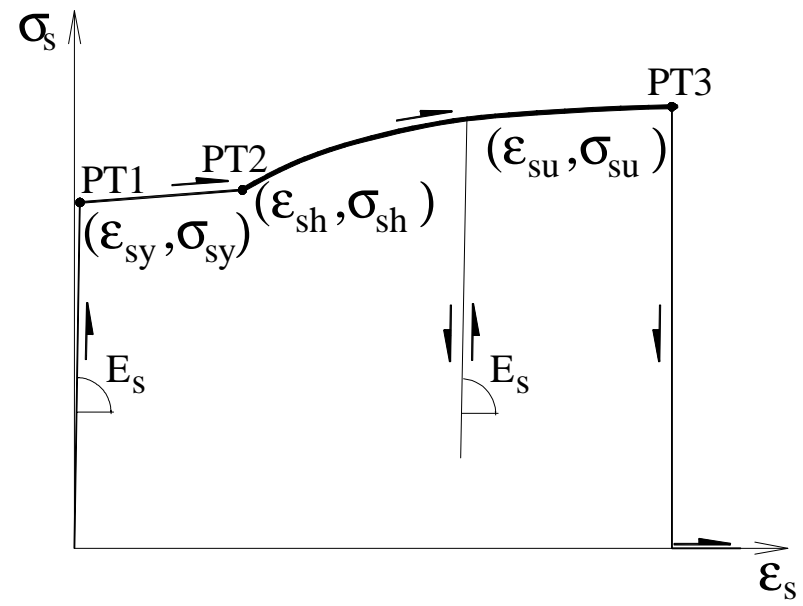

Figure 6 - Uniaxial constitutive model for the steel bars. 


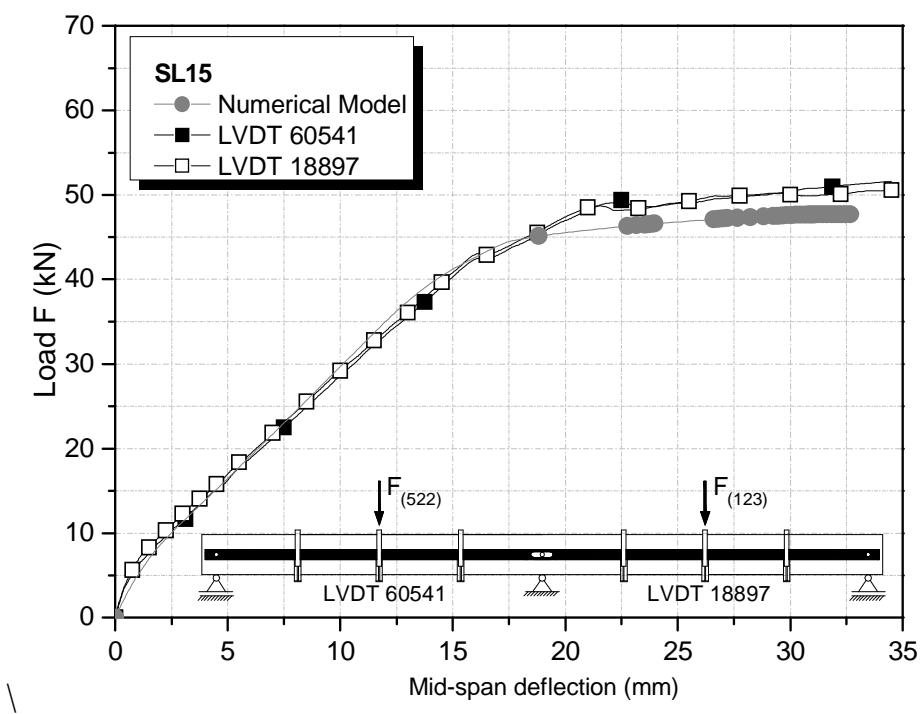

(a)

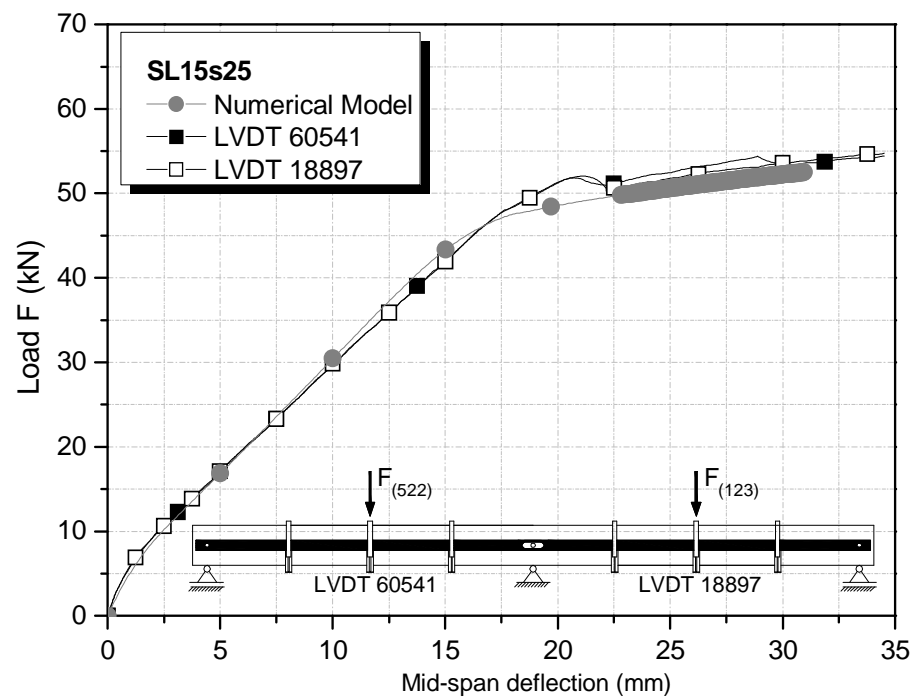

(b)

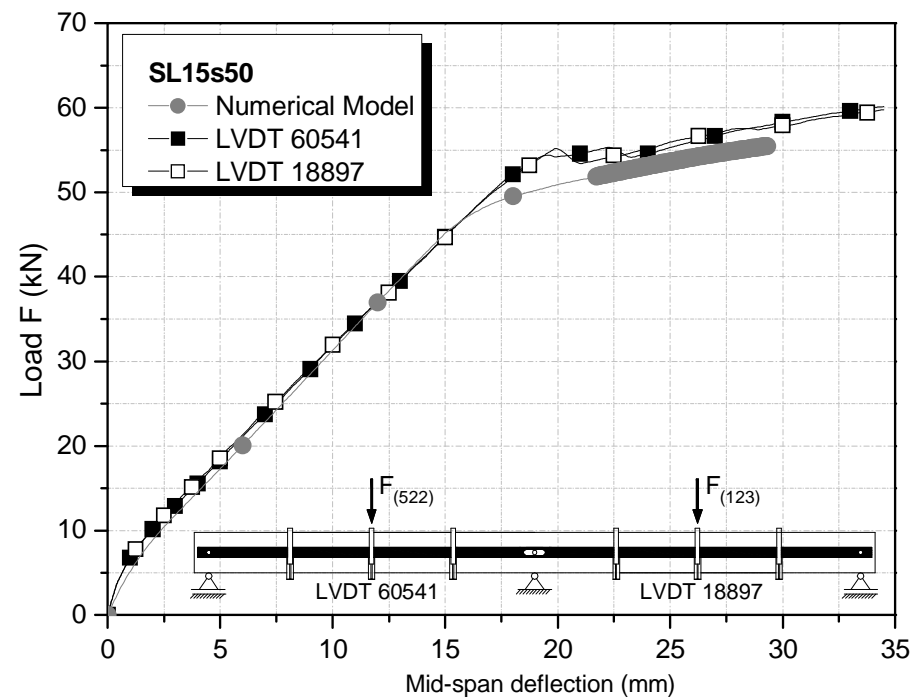

(c)

Figure 7 - Force-deflection relationship for the slabs: (a) SL15, (b) SL15s25 and (c) SL15s50. 


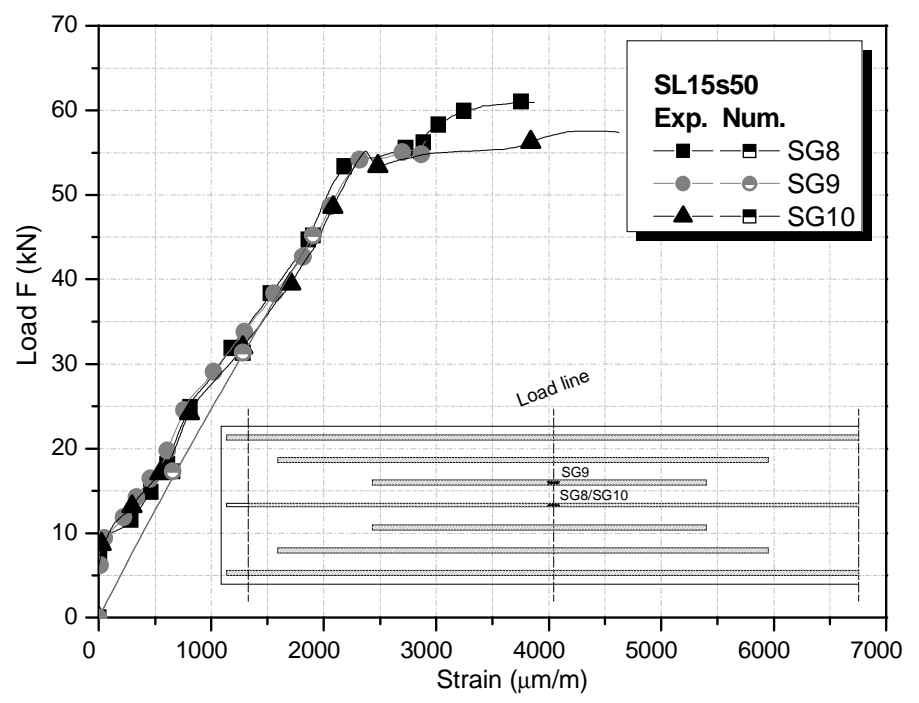

(a)

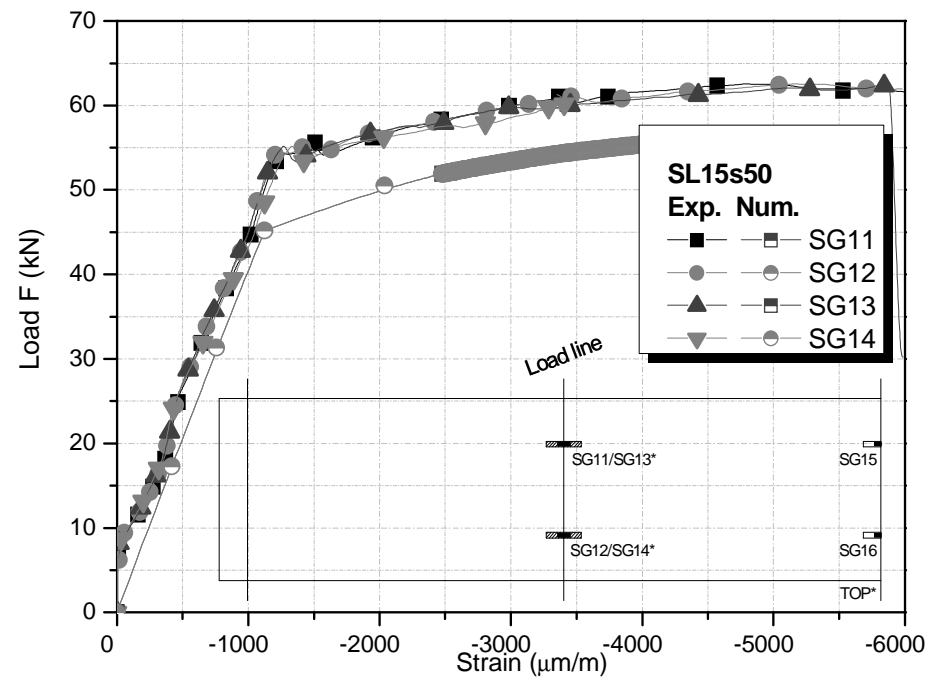

(b)

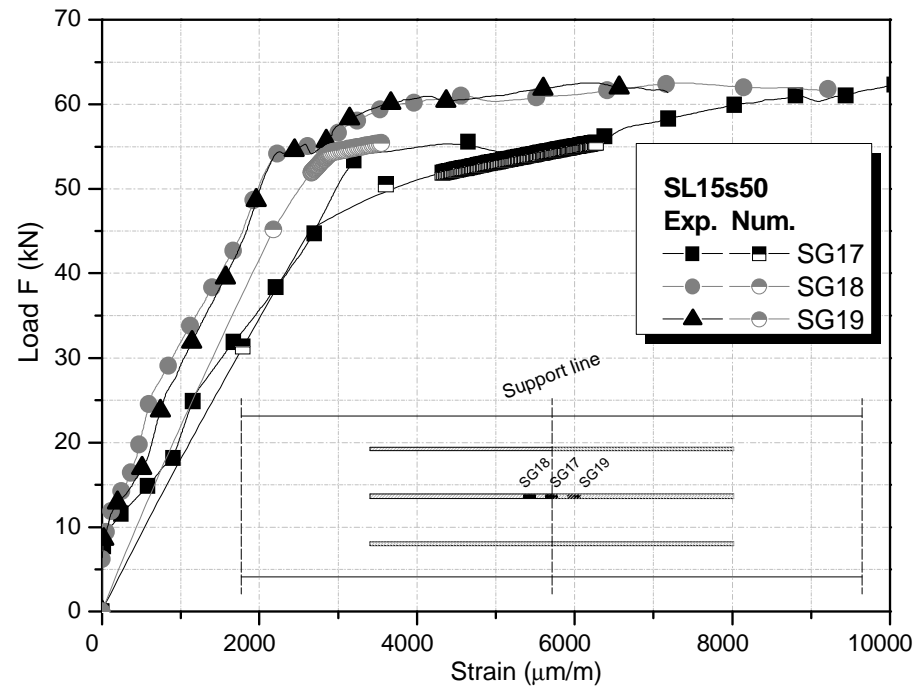

(c)

Figure 8 - SL15s50: (a) load - steel strain at slab loaded sections, (b) load - concrete strain at loaded sections and (c) load - CFRP laminate strain. 
(a)

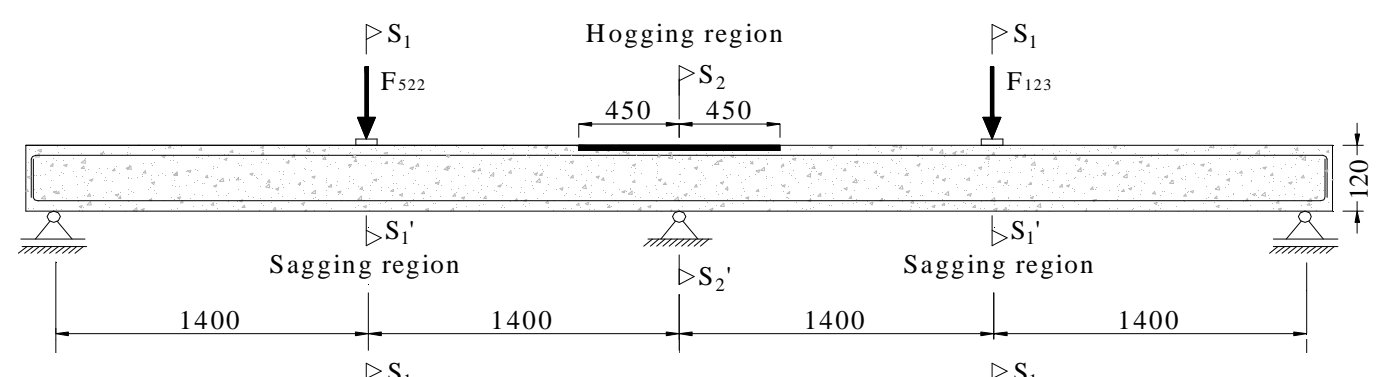

(b)
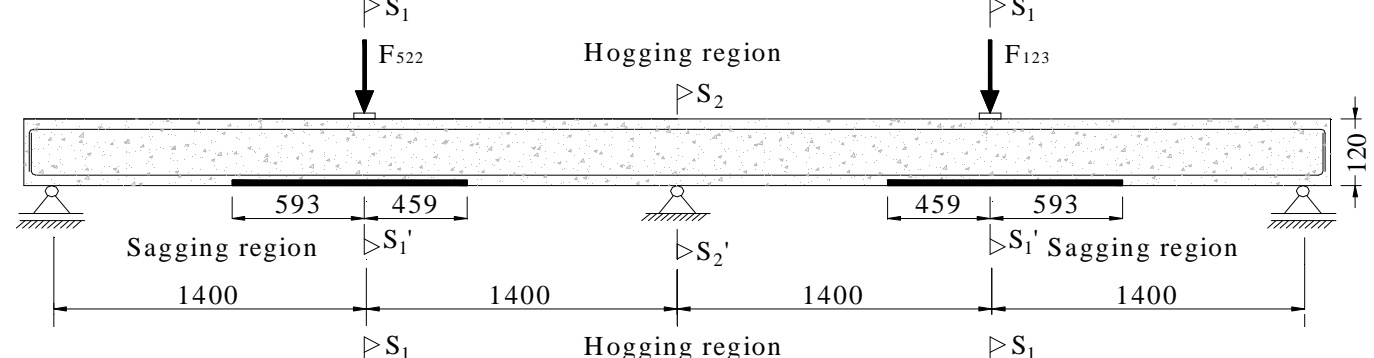

(c)

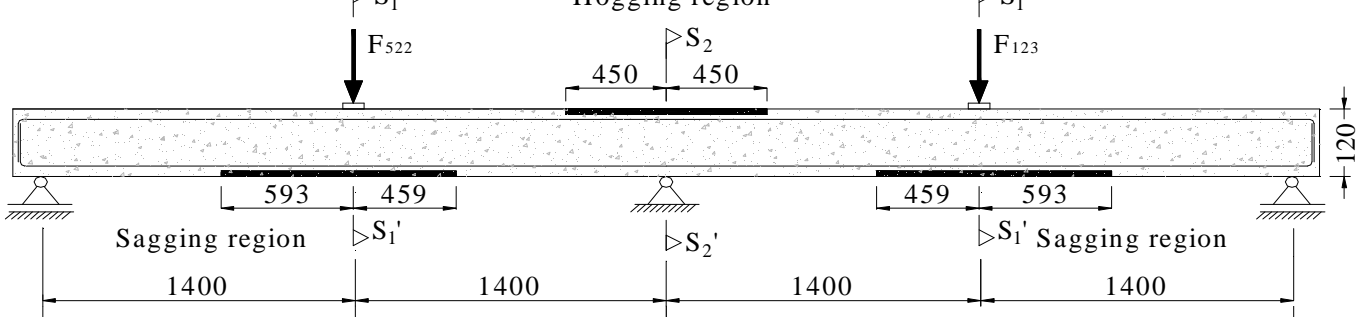

Figure 9 - Strengthening arrangements: NSM CFRP laminates applied in the (a) hogging region, (b) sagging region and (c) sagging and hogging regions (dimensions in $\mathrm{mm}$ ). 


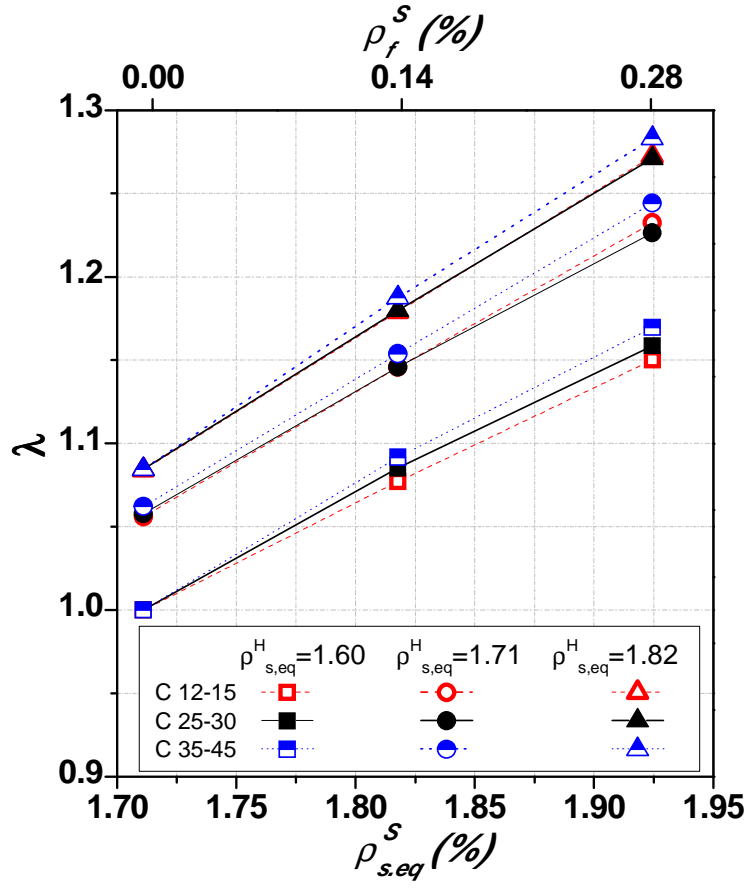

(a)

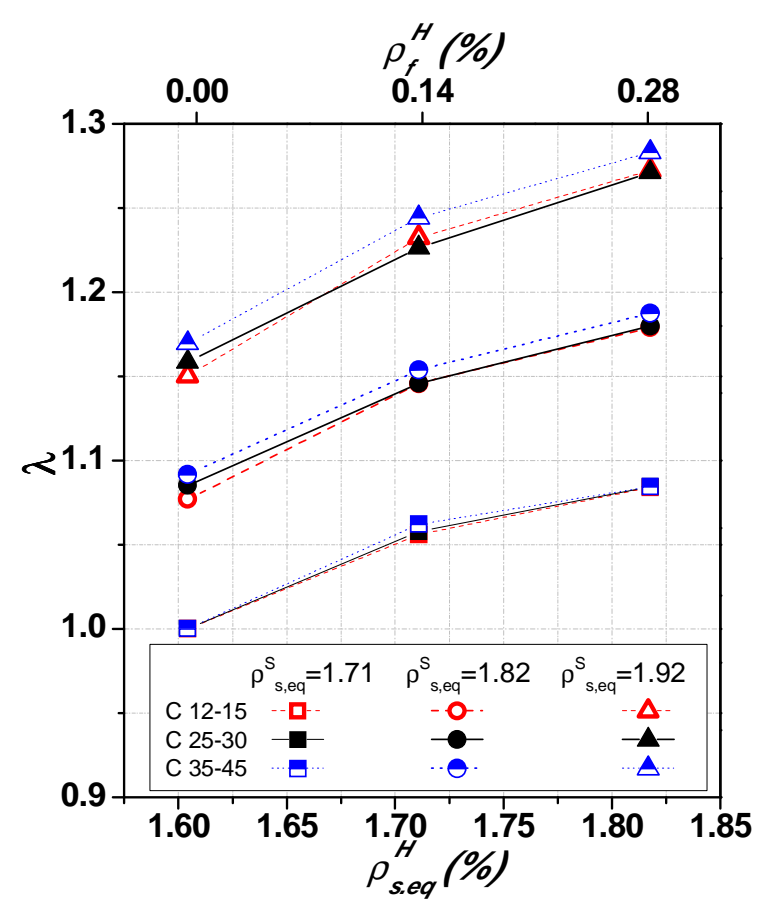

(b)

Figure 10 - Relationship between the load carrying capacity index and the equivalent reinforcement ratio in the (a) sagging and (b) hogging regions. 


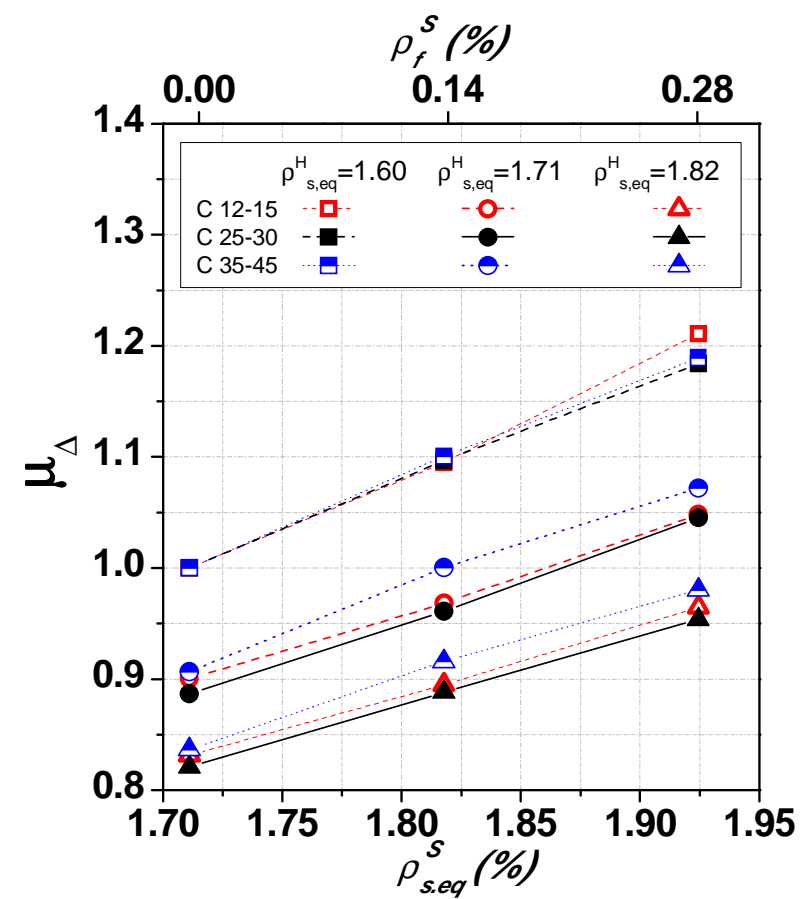

(a)

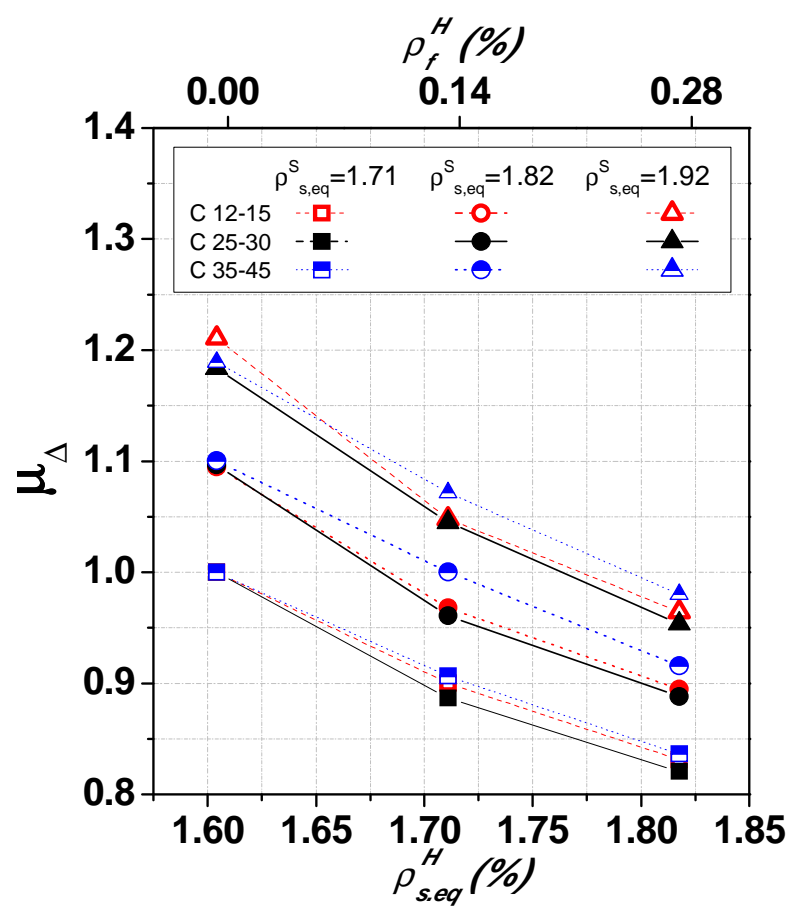

(b)

Figure 11 - Relationship between the displacement ductility index and the equivalent reinforcement ratio in the (a) sagging and (b) hogging regions. 


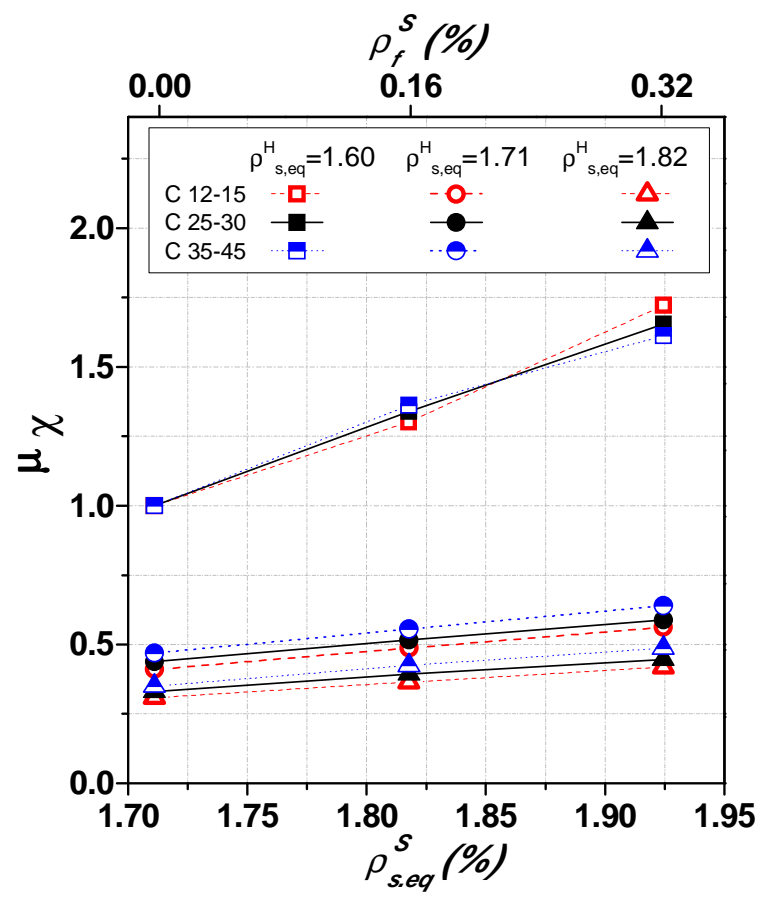

(a)

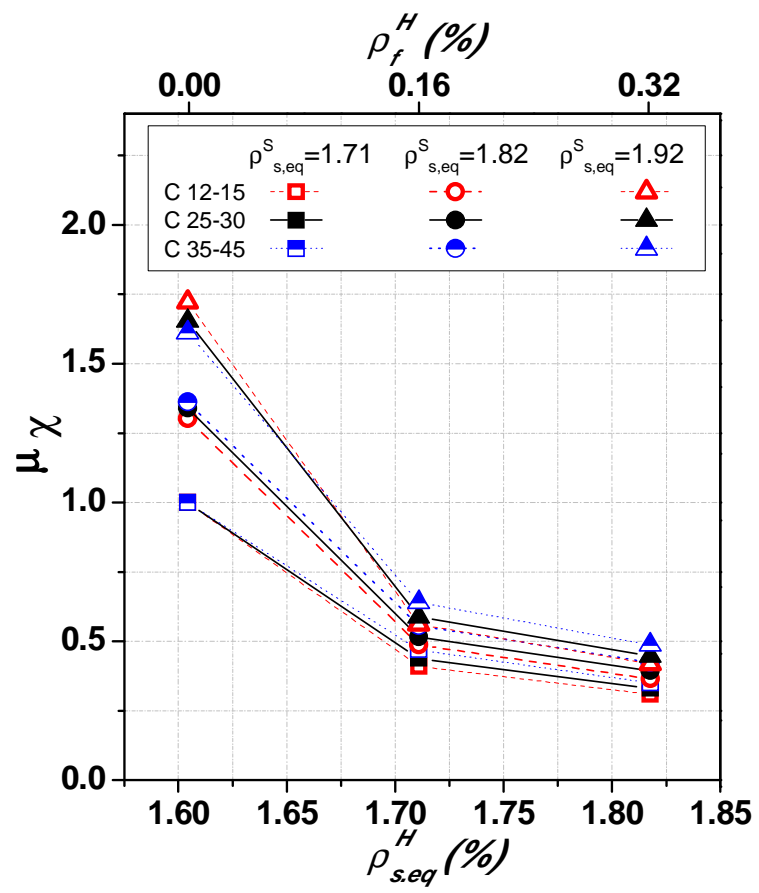

(b)

Figure 12 - Relationship between the rotational ductility index and the equivalent reinforcement ratio in the (a) sagging and (b) hogging regions. 


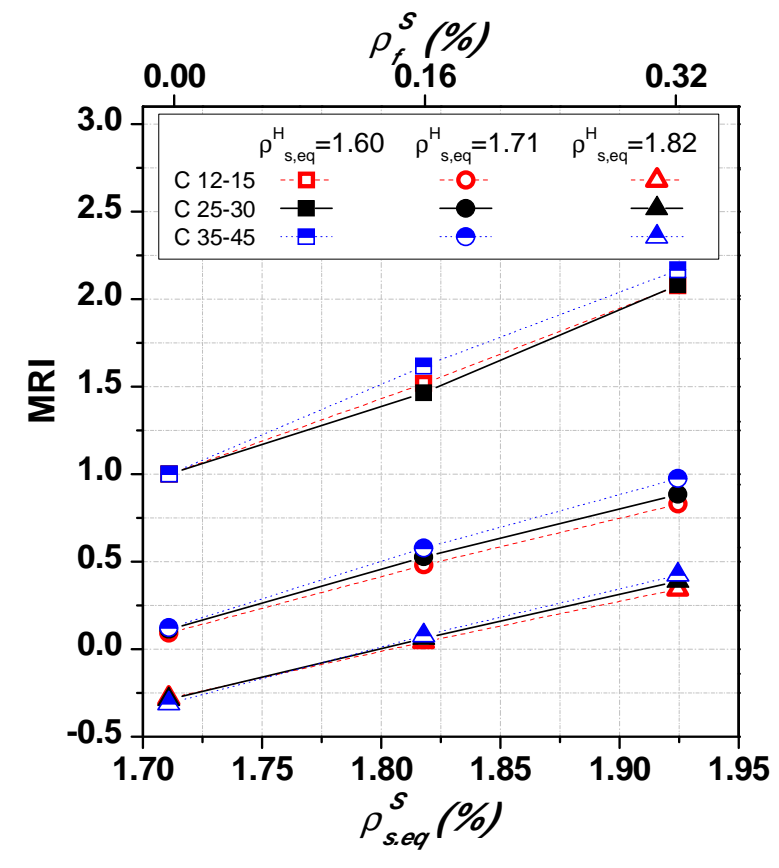

(a)

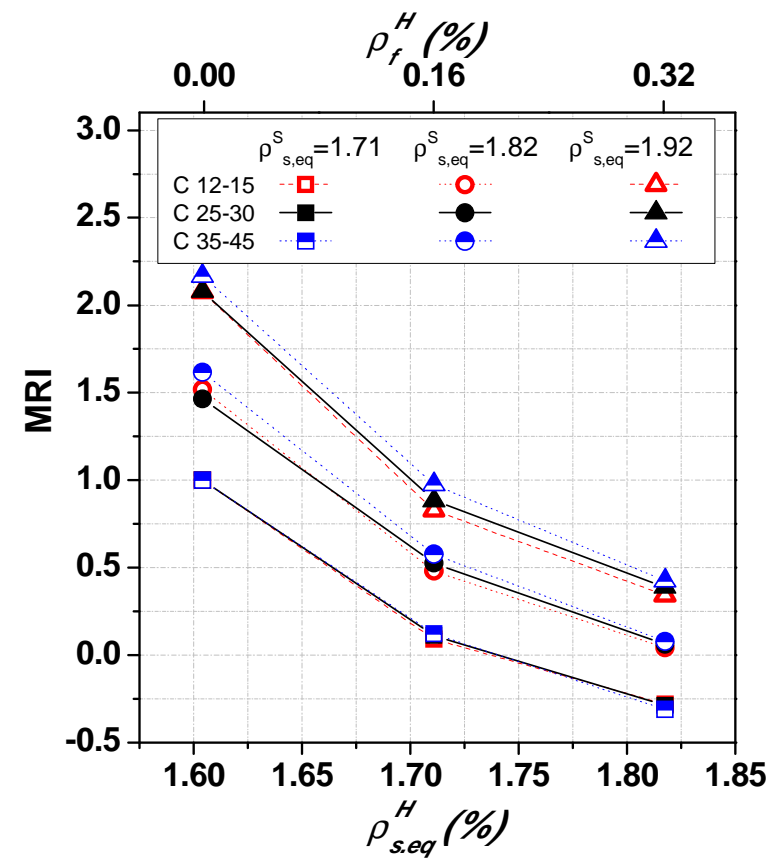

(b)

Figure 13 - Relationship between the moment redistribution index and the equivalent reinforcement ratio in the (a) sagging and (b) hogging regions. 


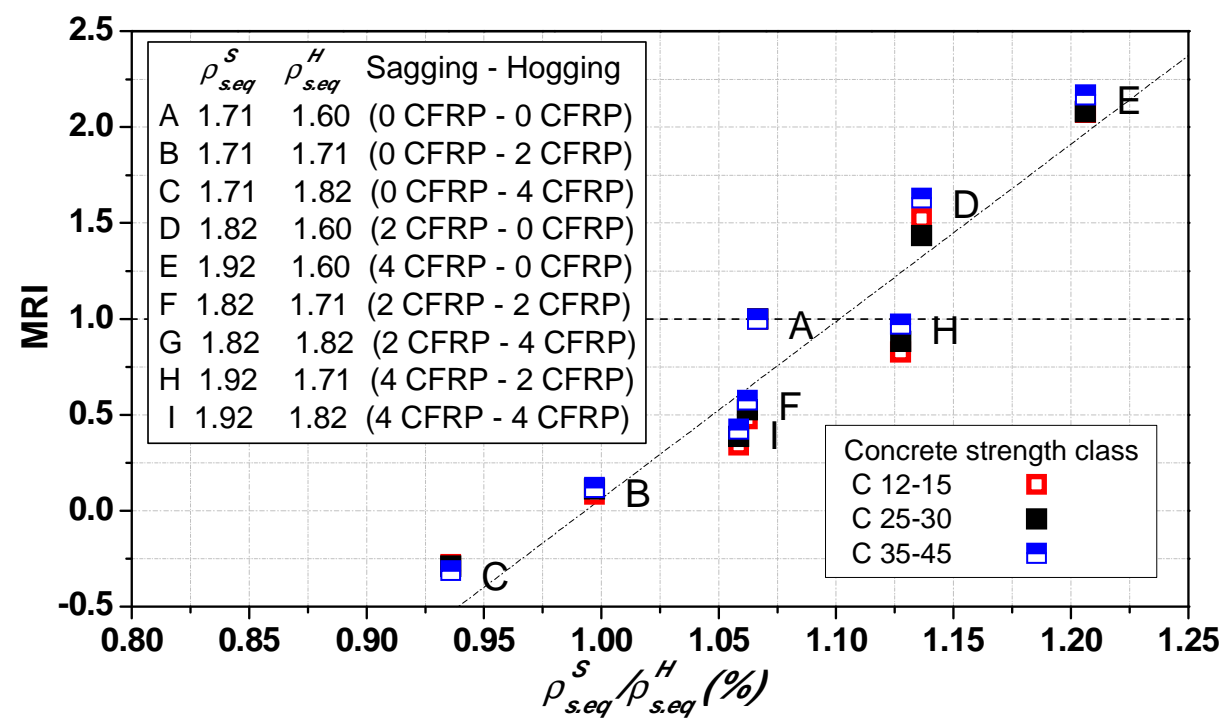

Figure 14 - Relationship between the moment redistribution index and $\rho_{s, e q}^{S} / \rho_{s, e q}^{H}$. 